\title{
Total synthesis of borrelidin
}

Tohru Nagamitsu, ${ }^{1}$ Daisuke Takano, ${ }^{1}$ Kaori Marumoto, ${ }^{1}$ Takeo Fukuda, ${ }^{1}$ Kentaro Furuya, ${ }^{1}$ Kazuhiko Otoguro, ${ }^{2}$ Kazuyoshi Takeda, ${ }^{3}$ Isao Kuwajima, ${ }^{4}$ Yoshihiro Harigaya,${ }^{1}$ and Satoshi Ōmura ${ }^{* 2,4}$

${ }^{1}$ School of Pharmacy, Kitasato University, 5-9-1 Shirokane, Minato-ku, Tokyo 108-8641, Japan

${ }^{2}$ The Kitasato Institute, 5-9-1 Shirokane, Minato-ku, Tokyo 108-8642, Japan

${ }^{3}$ Department of Medical Chemistry, Yokohama College of Pharmacy, 601 Matanocyo, Hodogayaku, Yokohama-shi,

Kanagawa 245-0066, Japan

${ }^{4}$ Kitasato Institute for Life Sciences and Graduate School of Infection Control Sciences, Kitasato University, 5-9-1 Shirokane, Minato-ku, Tokyo 108-8641, Japan

$\begin{array}{ll}{ }^{1} \mathrm{H} \text { and }{ }^{13} \mathrm{C} \text { NMR spectra of } \mathbf{2} & \text { NMR spectra } \\ { }^{1} \mathrm{H} \text { and }{ }^{13} \mathrm{C} \text { NMR spectra of } \mathbf{2}, & \text { S' } 45 \text { and } 46 \\ { }^{1} \mathrm{H} \text { and }{ }^{13} \mathrm{C} \text { NMR spectra of } \mathbf{3} & \mathrm{S}^{\prime} \text { 50 and } 51 \\ { }^{1} \mathrm{H} \text { and }{ }^{13} \mathrm{C} \text { NMR spectra of } \mathbf{4} & \mathrm{S}^{\prime} 25 \text { and } 26 \\ { }^{1} \mathrm{H} \text { and }{ }^{13} \mathrm{C} \text { NMR spectra of } \mathbf{6 a} & \mathrm{S}^{\prime} 39 \text { and } 40 \\ { }^{1} \mathrm{H} \text { and }{ }^{13} \mathrm{C} \text { NMR spectra of } \mathbf{6 b} & \mathrm{S}^{\prime} 1 \text { and } 2 \\ { }^{1} \mathrm{H} \text { and }{ }^{13} \mathrm{C} \text { NMR spectra of } 7 & \mathrm{~S}^{\prime} 3 \text { and } 4 \\ { }^{1} \mathrm{H} \text { and }{ }^{13} \mathrm{C} \text { NMR spectra of } \mathbf{8} & \mathrm{S}^{\prime} 5 \text { and } 6\end{array}$




\begin{tabular}{|c|c|}
\hline${ }^{1} \mathrm{H}$ and ${ }^{13} \mathrm{C}$ NMR spectra of $\mathbf{1 1}$ & S'9 and 10 \\
\hline${ }^{1} \mathrm{H}$ and ${ }^{13} \mathrm{C}$ NMR spectra of $\mathbf{1 2}$ & S'11 and 12 \\
\hline${ }^{1} \mathrm{H}$ and ${ }^{13} \mathrm{C}$ NMR spectra of $\mathbf{1 3}$ & $S^{\prime} 13$ and 14 \\
\hline${ }^{1} \mathrm{H}$ and ${ }^{13} \mathrm{C}$ NMR spectra of $\mathbf{1 4}$ & $S^{\prime} 15$ and 16 \\
\hline${ }^{1} \mathrm{H}$ and ${ }^{13} \mathrm{C}$ NMR spectra of $\mathbf{1 4 a}$ & $S^{\prime} 17$ and 18 \\
\hline${ }^{1} \mathrm{H}$ and ${ }^{13} \mathrm{C}$ NMR spectra of $\mathbf{1 4 b}$ & S'19 and 20 \\
\hline${ }^{1} \mathrm{H}$ and ${ }^{13} \mathrm{C}$ NMR spectra of 15 & $S^{\prime} 21$ and 22 \\
\hline${ }^{1} \mathrm{H}$ and ${ }^{13} \mathrm{C}$ NMR spectra of $\mathbf{1 6}$ & S'23 and 24 \\
\hline${ }^{1} \mathrm{H}$ and ${ }^{13} \mathrm{C}$ NMR spectra of $\mathbf{1 9}$ & S'27 and 28 \\
\hline${ }^{1} \mathrm{H}$ and ${ }^{13} \mathrm{C}$ NMR spectra of 21 & S'29 and 30 \\
\hline${ }^{1} \mathrm{H}$ and ${ }^{13} \mathrm{C}$ NMR spectra of 25 & S'31 and 32 \\
\hline${ }^{1} \mathrm{H}$ and ${ }^{13} \mathrm{C}$ NMR spectra of 26 & S'33 and 34 \\
\hline${ }^{1} \mathrm{H}$ and ${ }^{13} \mathrm{C}$ NMR spectra of 27 & S'35 and 36 \\
\hline${ }^{1} \mathrm{H}$ and ${ }^{13} \mathrm{C}$ NMR spectra of $\mathbf{2 8}$ & S'37 and 38 \\
\hline${ }^{1} \mathrm{H}$ and ${ }^{13} \mathrm{C}$ NMR spectra of 29a & S' 38 and 39 \\
\hline${ }^{1} \mathrm{H}$ and ${ }^{13} \mathrm{C}$ NMR spectra of $\mathbf{2 9 b}$ & $S^{\prime \prime} 17$ and 18 \\
\hline${ }^{1} \mathrm{H}$ and ${ }^{13} \mathrm{C}$ NMR spectra of $\mathbf{3 0}$ & $S ', 40$ and 41 \\
\hline${ }^{1} \mathrm{H}$ and ${ }^{13} \mathrm{C}$ NMR spectra of $\mathbf{3 0 a}$ & S', 42 and 43 \\
\hline${ }^{1} \mathrm{H}$ and ${ }^{13} \mathrm{C}$ NMR spectra of $\mathbf{3 1}$ & S', 44 and 45 \\
\hline${ }^{1} \mathrm{H}$ and ${ }^{13} \mathrm{C}$ NMR spectra of $\mathbf{3 1 a}$ & S' 46 and 47 \\
\hline${ }^{1} \mathrm{H}$ and ${ }^{13} \mathrm{C}$ NMR spectra of $\mathbf{3 1 b}$ & $S ', 48$ and 49 \\
\hline${ }^{1} \mathrm{H}$ and ${ }^{13} \mathrm{C}$ NMR spectra of $\mathbf{3 2}$ & $S^{\prime} 41$ and 42 \\
\hline
\end{tabular}


${ }^{1} \mathrm{H}$ and ${ }^{13} \mathrm{C}$ NMR spectra of $\mathbf{3 2 a}$

S' 43 and 44

${ }^{1} \mathrm{H}$ and ${ }^{13} \mathrm{C}$ NMR spectra of $\mathbf{3 6}$

S'"52 and 53

${ }^{1} \mathrm{H}$ and ${ }^{13} \mathrm{C}$ NMR spectra of $\mathbf{3 7}$

S'47 and 48

${ }^{1} \mathrm{H}$ and ${ }^{13} \mathrm{C}$ NMR spectra of $\mathbf{3 8}$

S' 49 and 50

${ }^{1} \mathrm{H}$ NMR spectra of $\mathbf{4 3}$

S',9

${ }^{1} \mathrm{H}$ and ${ }^{13} \mathrm{C}$ NMR spectra of $\mathbf{4 4}$

S' 1 and 2

${ }^{1} \mathrm{H}$ and ${ }^{13} \mathrm{C}$ NMR spectra of $\mathbf{4 5}$

S', 3 and 4

${ }^{1} \mathrm{H}$ and ${ }^{13} \mathrm{C}$ NMR spectra of $\mathbf{4 6}$

S', 5 and 6

${ }^{1} \mathrm{H}$ and ${ }^{13} \mathrm{C}$ NMR spectra of $\mathbf{4 7}$

S', 7 and 8

${ }^{1} \mathrm{H}$ and ${ }^{13} \mathrm{C}$ NMR spectra of $\mathbf{4 8}$

S' 10 and 11

${ }^{1} \mathrm{H}$ and ${ }^{13} \mathrm{C}$ NMR spectra of $\mathbf{5 1}$

S' 12 and 13

${ }^{1} \mathrm{H}$ NMR spectra of $\mathbf{5 3}$

${ }^{1} \mathrm{H}$ and ${ }^{13} \mathrm{C}$ NMR spectra of $\mathbf{5 5}$

$\mathrm{S}$ ' 14

${ }^{1} \mathrm{H}$ and ${ }^{13} \mathrm{C}$ NMR spectra of $\mathbf{5 7}$

${ }^{1} \mathrm{H}$ NMR spectra of $\mathbf{5 8 a}$

S' 15 and 16

S', 36 and 37

S',33

${ }^{1} \mathrm{H}$ and ${ }^{13} \mathrm{C}$ NMR spectra of $\mathbf{5 8 b}$

S', 34 and 35

${ }^{1} \mathrm{H}$ NMR spectra of 59a

S'19

${ }^{1} \mathrm{H}$ and ${ }^{13} \mathrm{C}$ NMR spectra of 59b

S' 20 and 21

${ }^{1} \mathrm{H}$ NMR spectra of $\mathbf{6 0 a}$

$\mathrm{S}$ ',22

${ }^{1} \mathrm{H}$ and ${ }^{13} \mathrm{C}$ NMR spectra of $\mathbf{6 0 b}$

S' 23 and 24

${ }^{1} \mathrm{H}$ NMR spectra of $61 \mathrm{a}$

$\mathrm{S}, 25$

${ }^{1} \mathrm{H}$ and ${ }^{13} \mathrm{C}$ NMR spectra of $\mathbf{6 1 b}$ 
${ }^{1} \mathrm{H}$ and ${ }^{13} \mathrm{C}$ NMR spectra of $\mathbf{6 1 b}$,

${ }^{1} \mathrm{H}$ NMR spectra of $\mathbf{6 2 a}$

${ }^{1} \mathrm{H}$ and ${ }^{13} \mathrm{C}$ NMR spectra of $\mathbf{6 2 b}$

${ }^{1} \mathrm{H}$ and ${ }^{13} \mathrm{C}$ NMR spectra of 64

${ }^{1} \mathrm{H}$ and ${ }^{13} \mathrm{C}$ NMR spectra of synthetic (1)

${ }^{1} \mathrm{H}$ and ${ }^{13} \mathrm{C}$ NMR spectra of natural (1)
S', 29 and 30

$\mathrm{S}$ ',28

S' 31 and 32

S', 54 and 55

S''56 and 57

S',58 and 59 


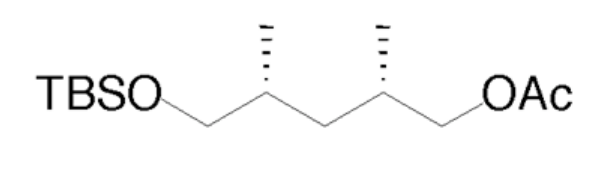

$6 a$

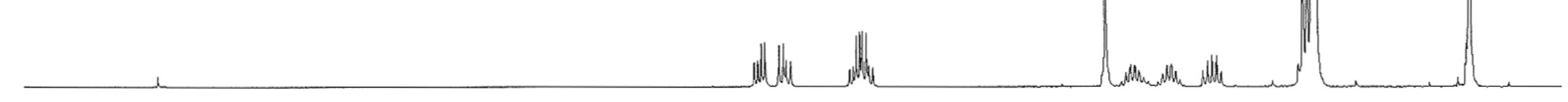

PPM

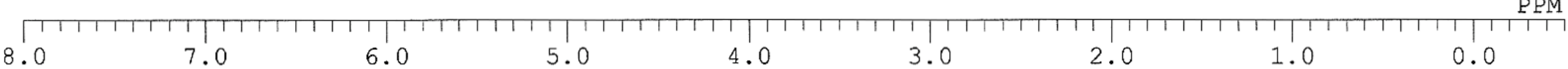




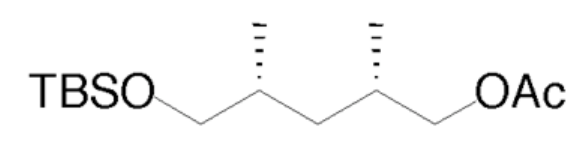

$6 a$

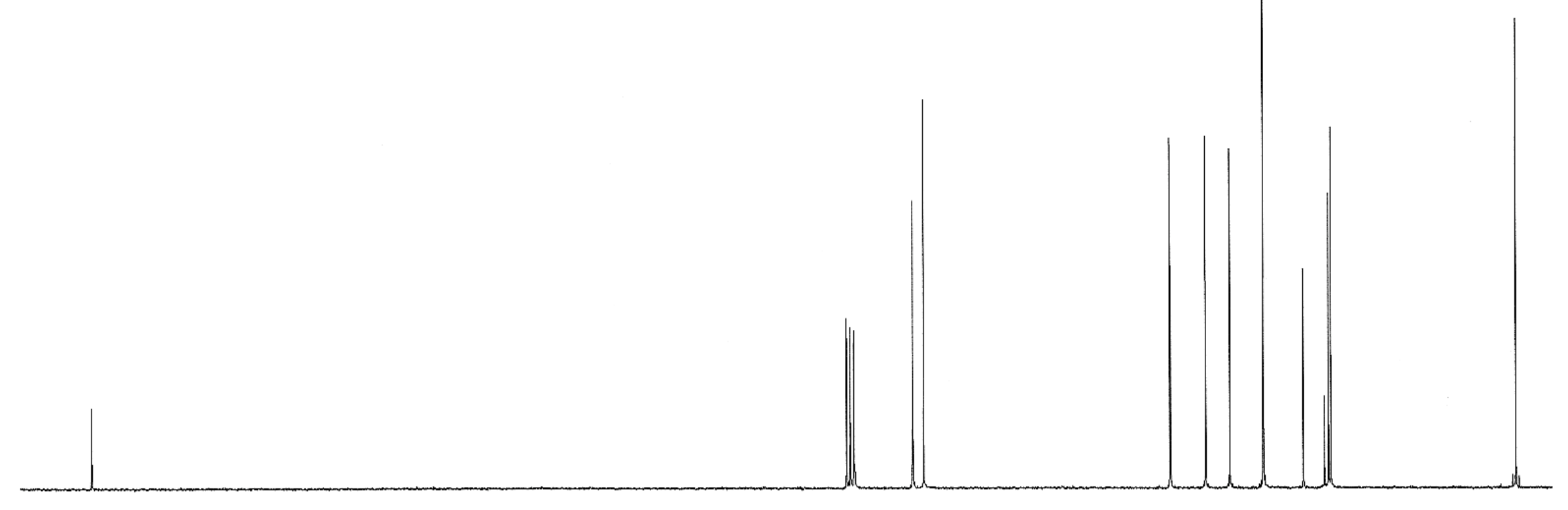

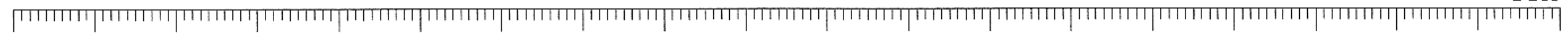

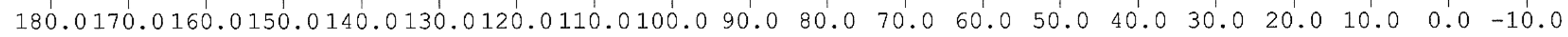




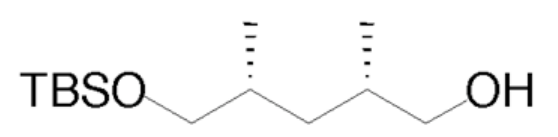

$6 b$

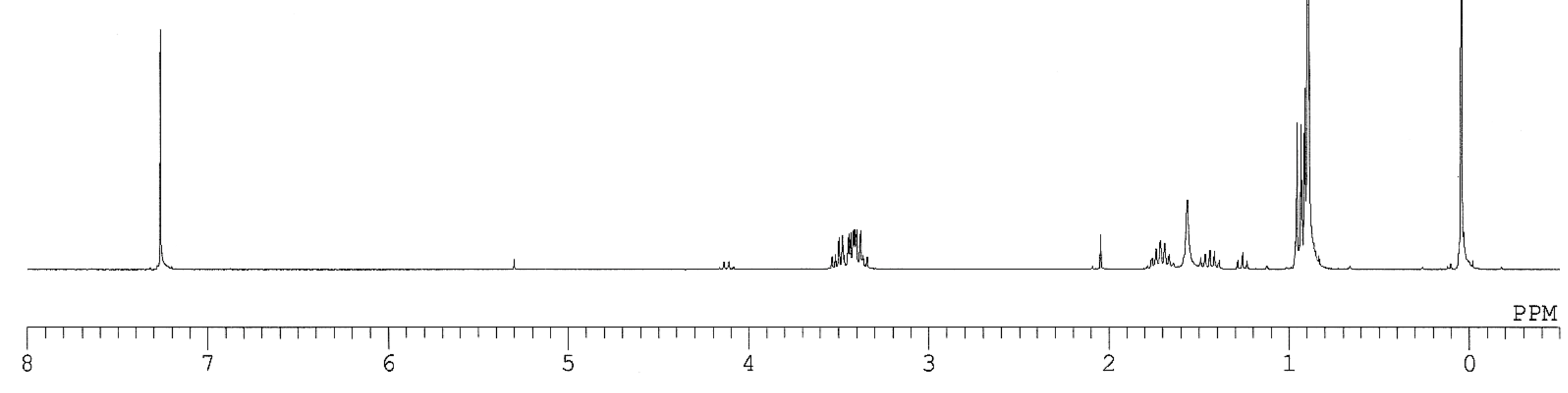




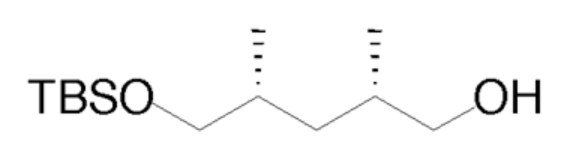

\section{6b}

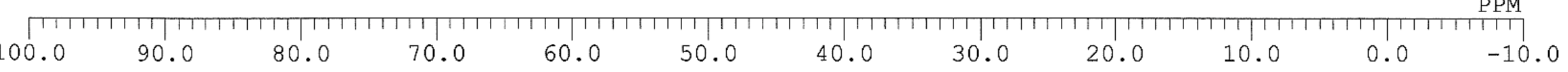



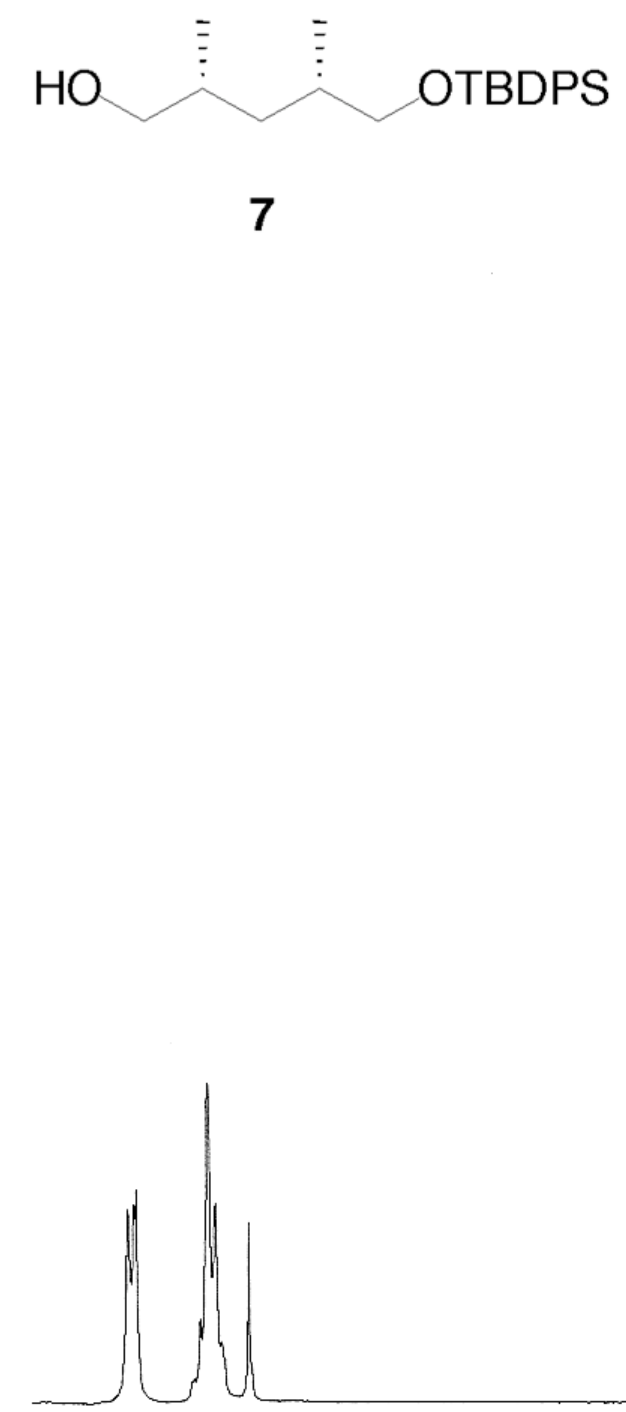
J)

PPM

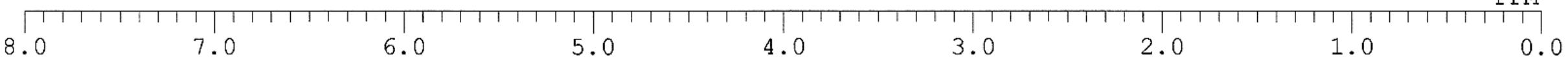



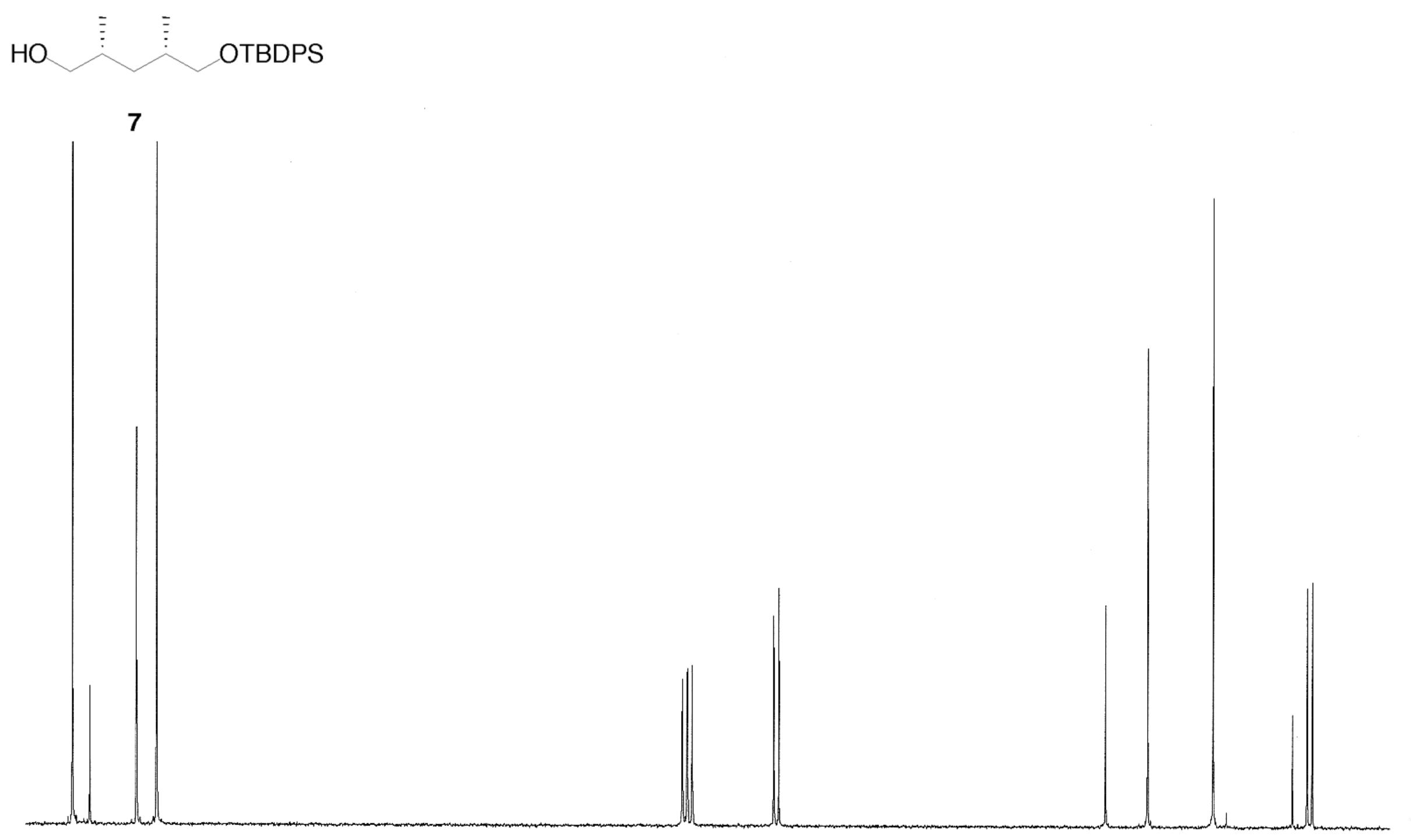

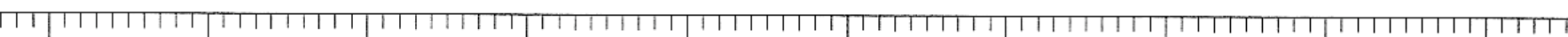

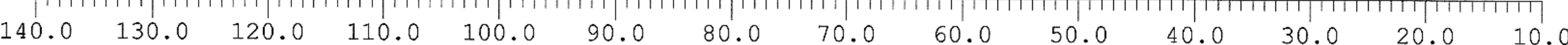




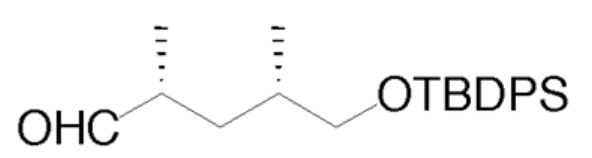

8

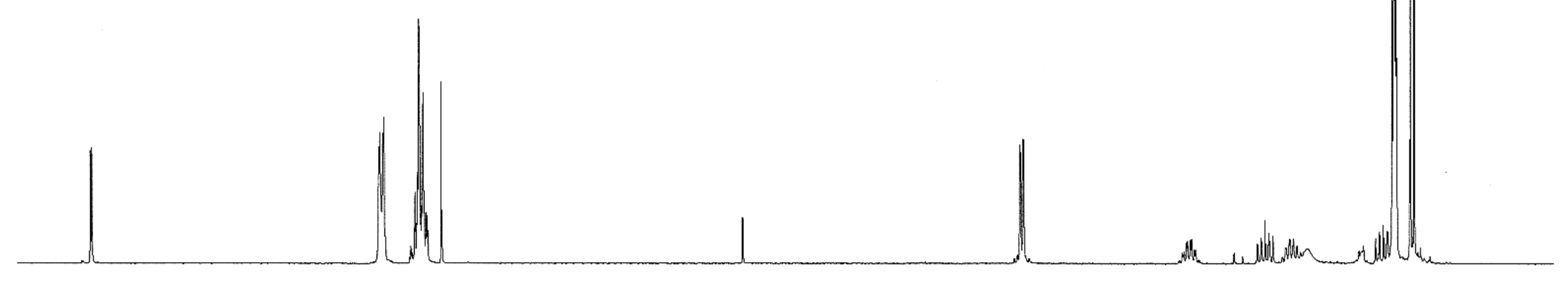

PPM

\begin{tabular}{|c|c|c|c|c|c|c|c|c|c|}
\hline \multirow{2}{*}{10.0} & 111 & 11 & & & & & & 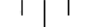 & 11 \\
\hline & 9.0 & 8.0 & 7.0 & 6.0 & 5.0 & 4.0 & 3.0 & 2.0 & 1.0 \\
\hline
\end{tabular}




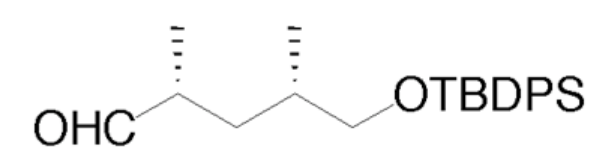

8

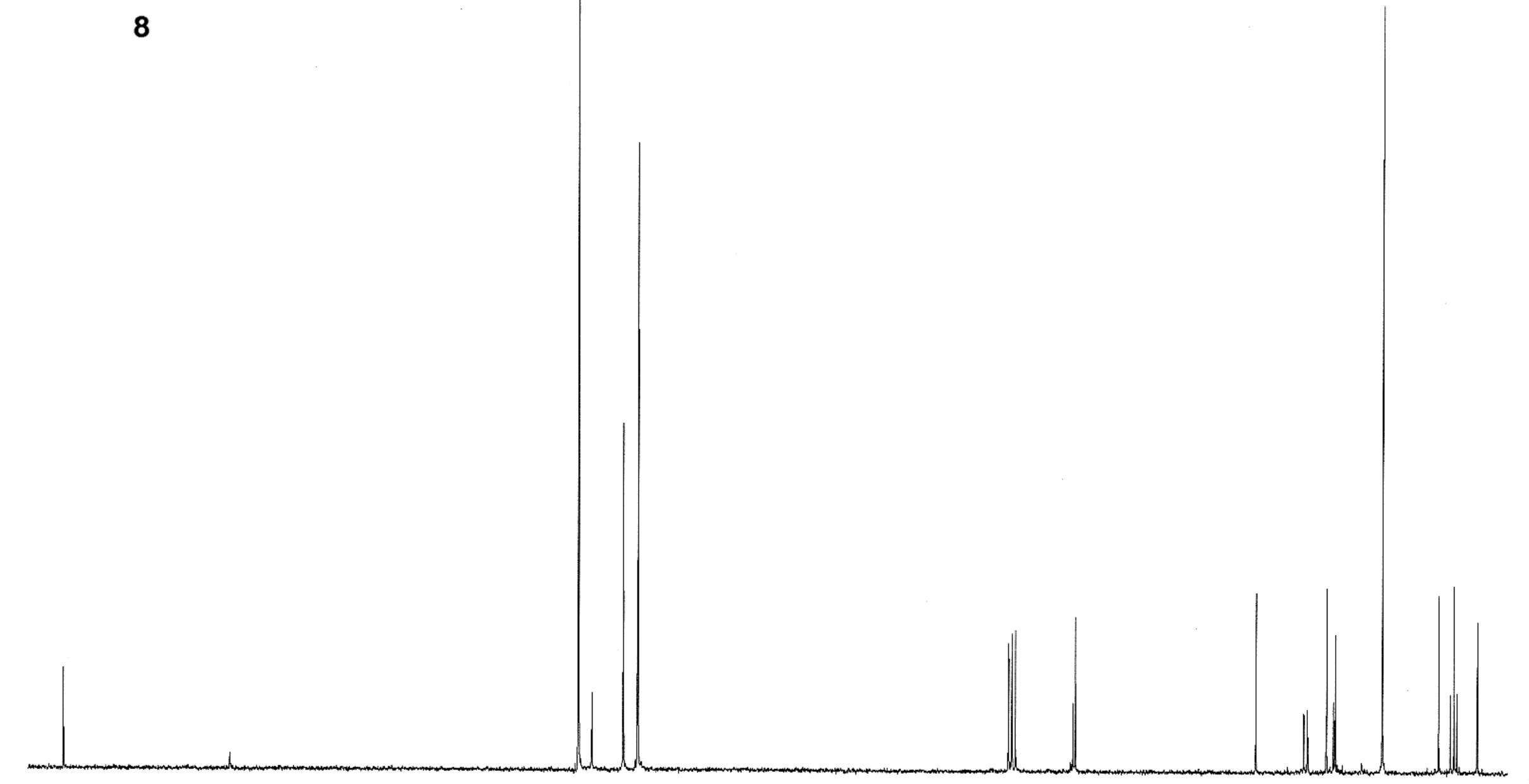

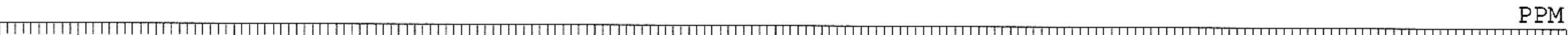
$210.0200 .0190 .0180 .0170 .0160 .0150 .0140 .0130 .0120 .0110 .0100 .090 .0 \quad 80.070 .0 \quad 60.0 \quad 50.0 \quad 40.0 \quad 30.020 .0 \quad 10.0$ 


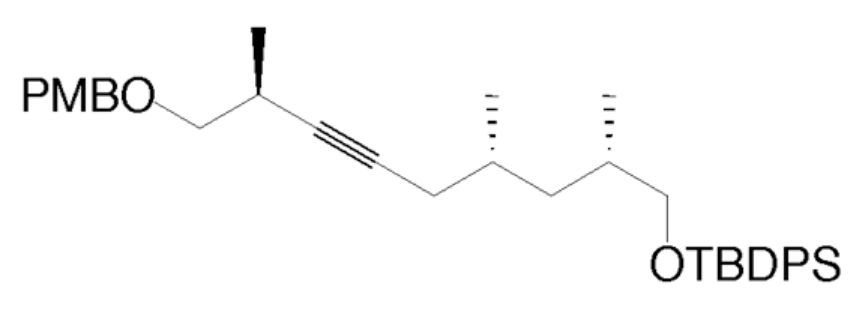

11

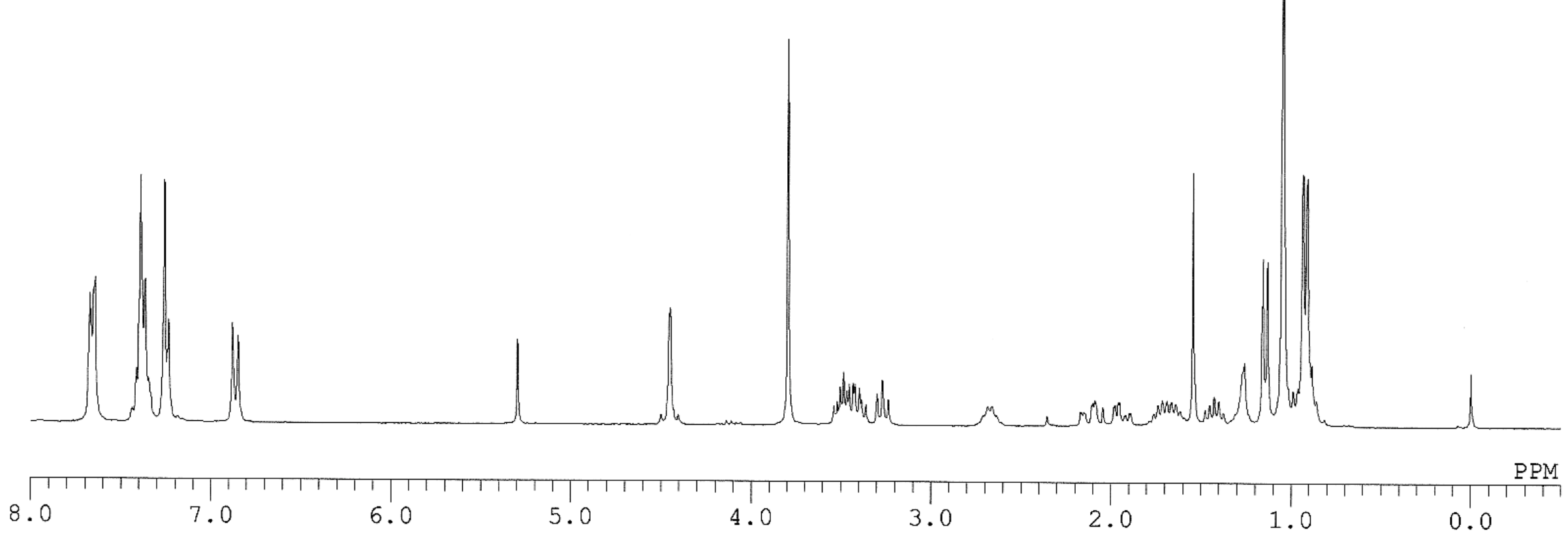




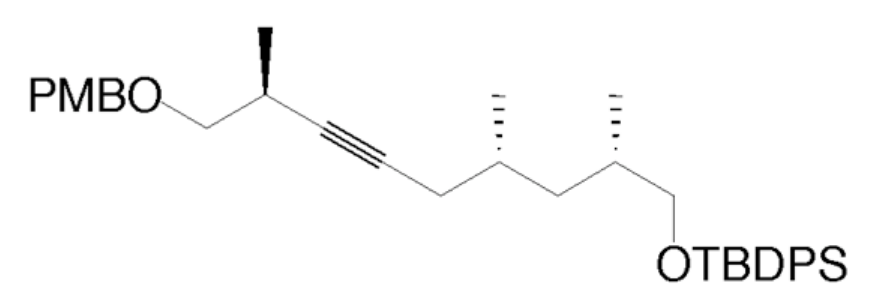

11

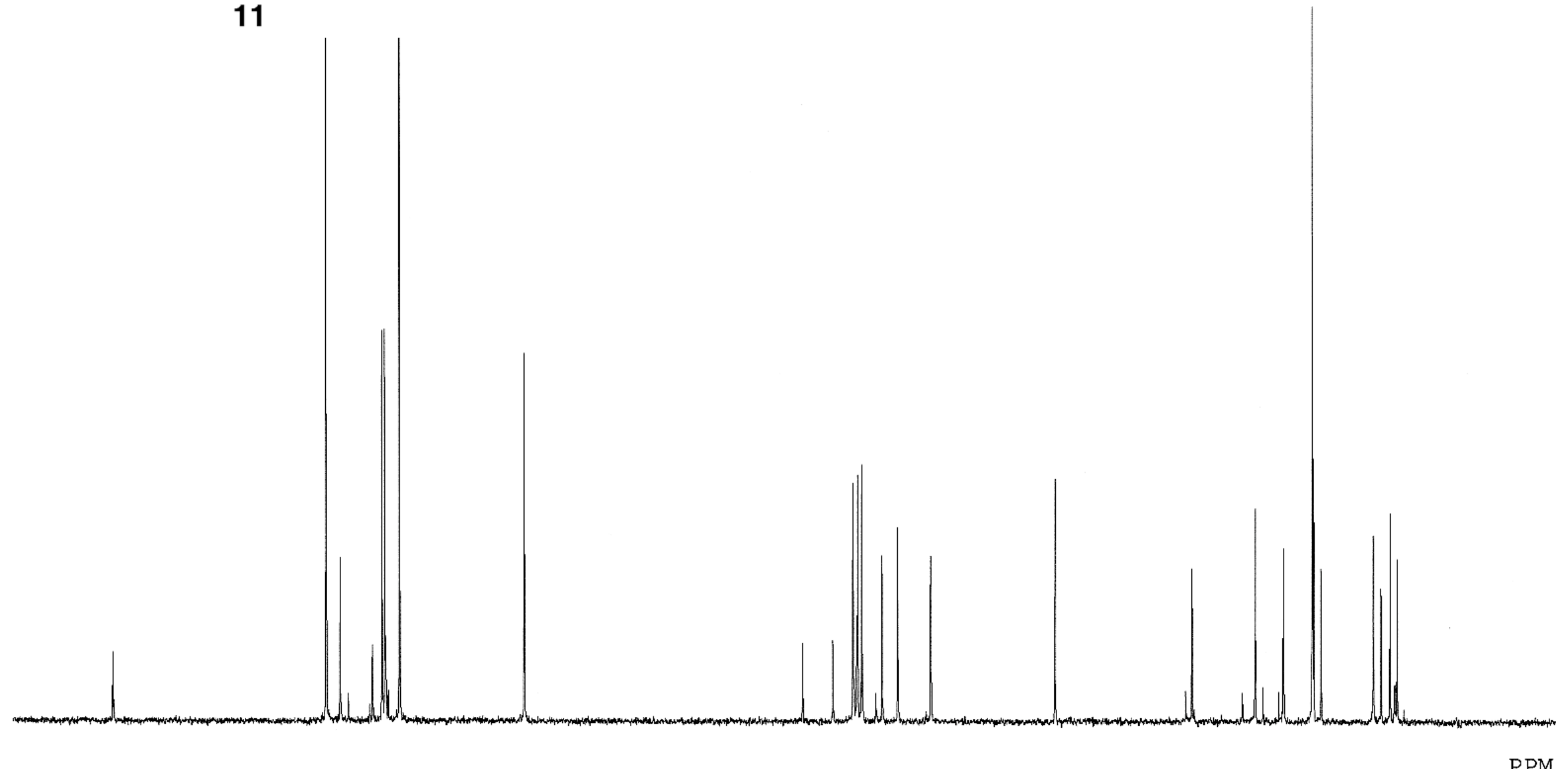

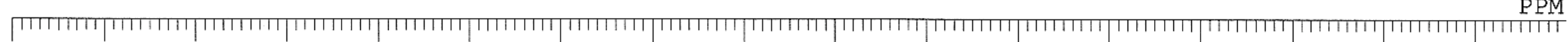
$\begin{array}{lllllllllllllllll}170.0 & 160.0 & 150.0 & 140.0 & 130.0 & 120.0 & 110.0 & 100.0 & 90.0 & 80.0 & 70.0 & 60.0 & 50.0 & 40.0 & 30.0 & 20.0 & 10.0\end{array}$ 


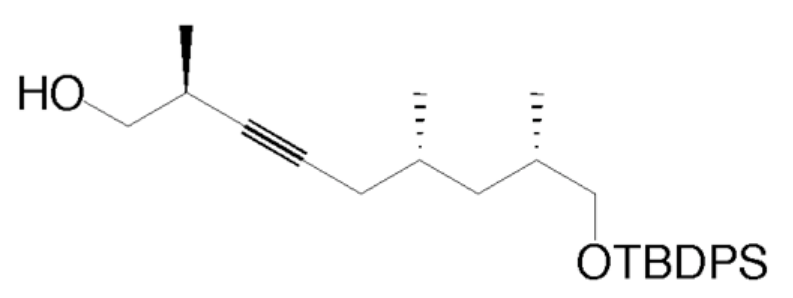

12

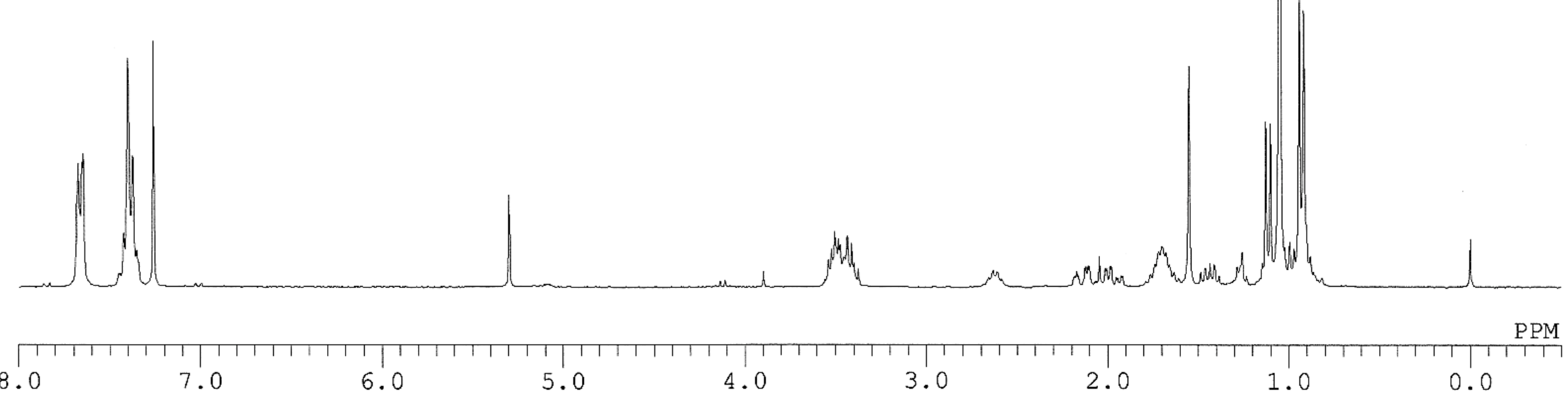




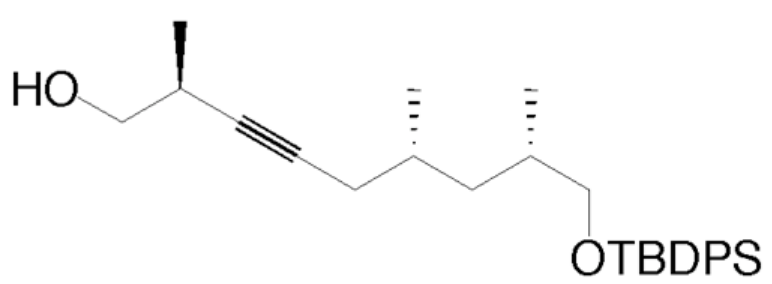

12
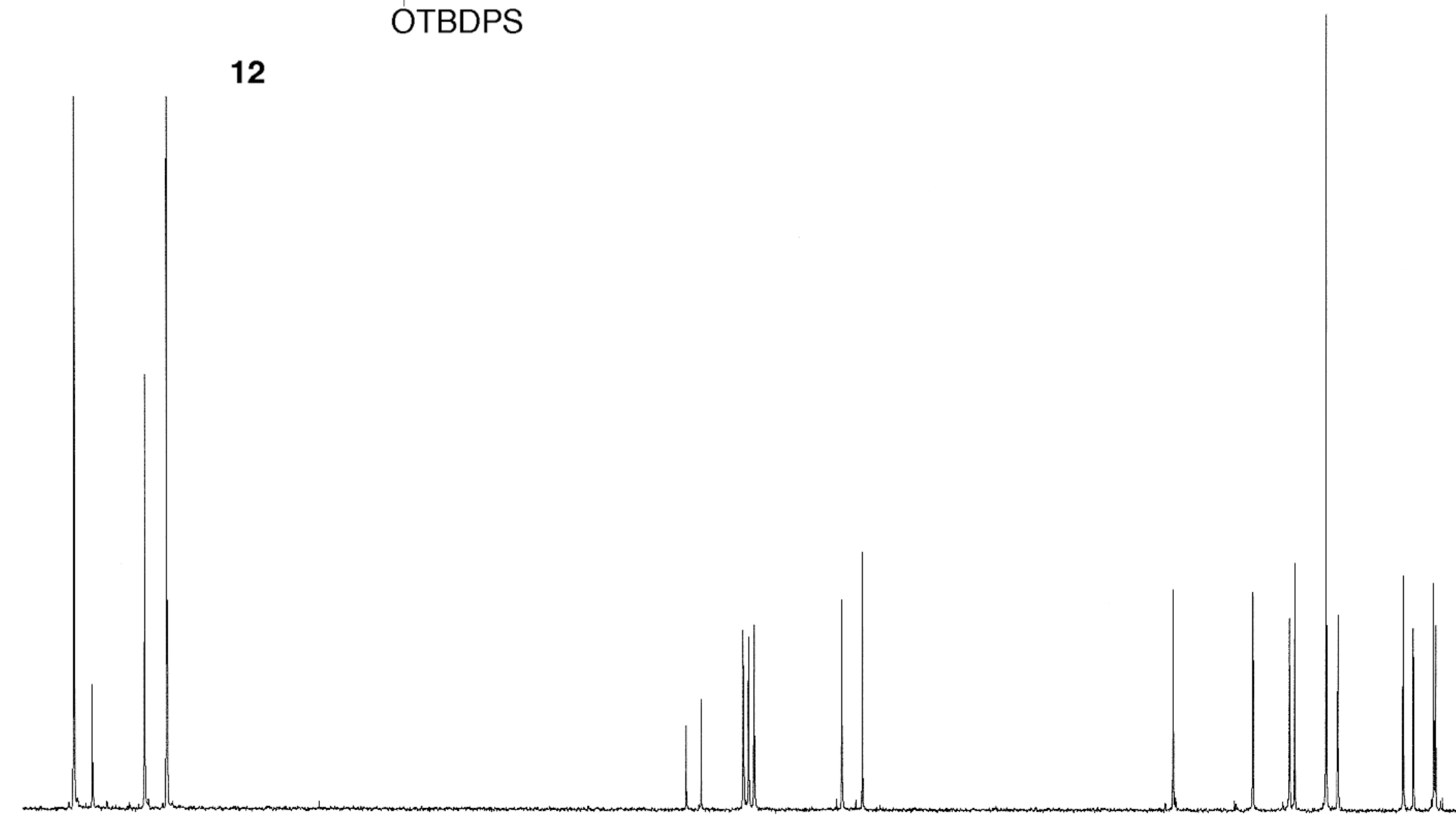
140.0
130.0
$110.0 \quad 100.0$
90.0
80.0
70.0
60.0
50.0
40.0
30.0
20.0
10.0 


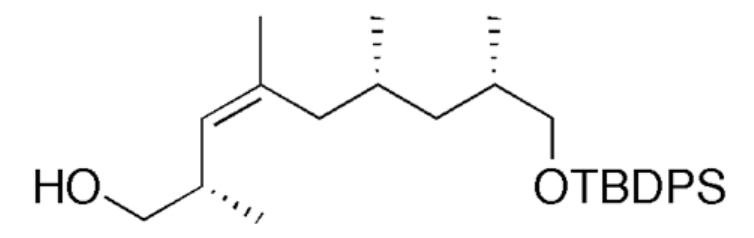

13

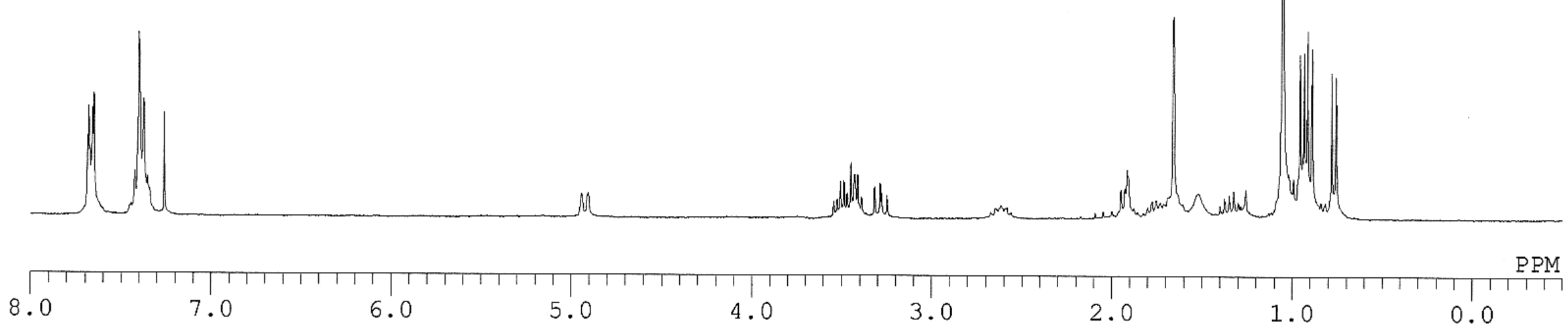

$\mathrm{S}^{\prime}$

13 


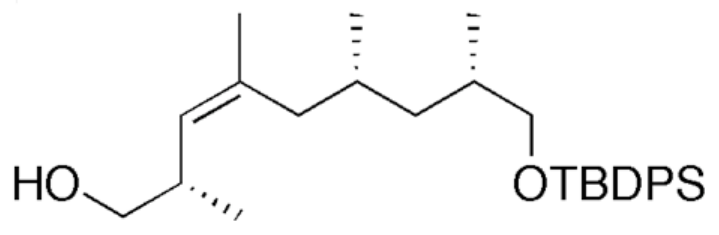

13

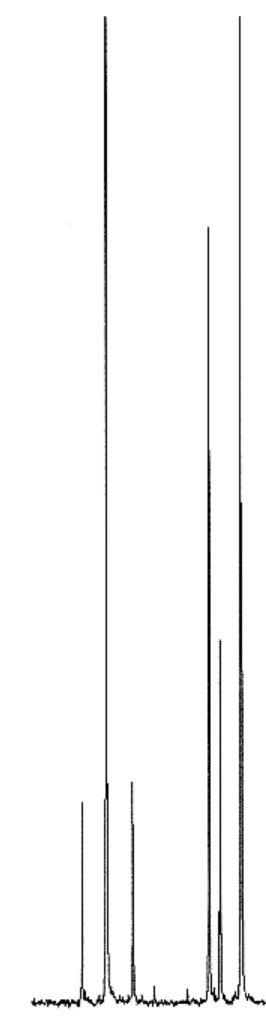

PPM

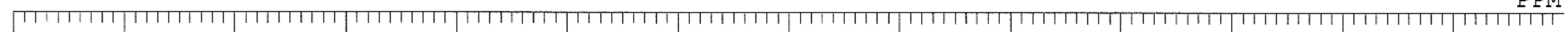
140.0
130.0120 .0
110.0100 .0
90.0
80.0
70.0
60.0
50.0
40.0
30.0
20.0
10.0 

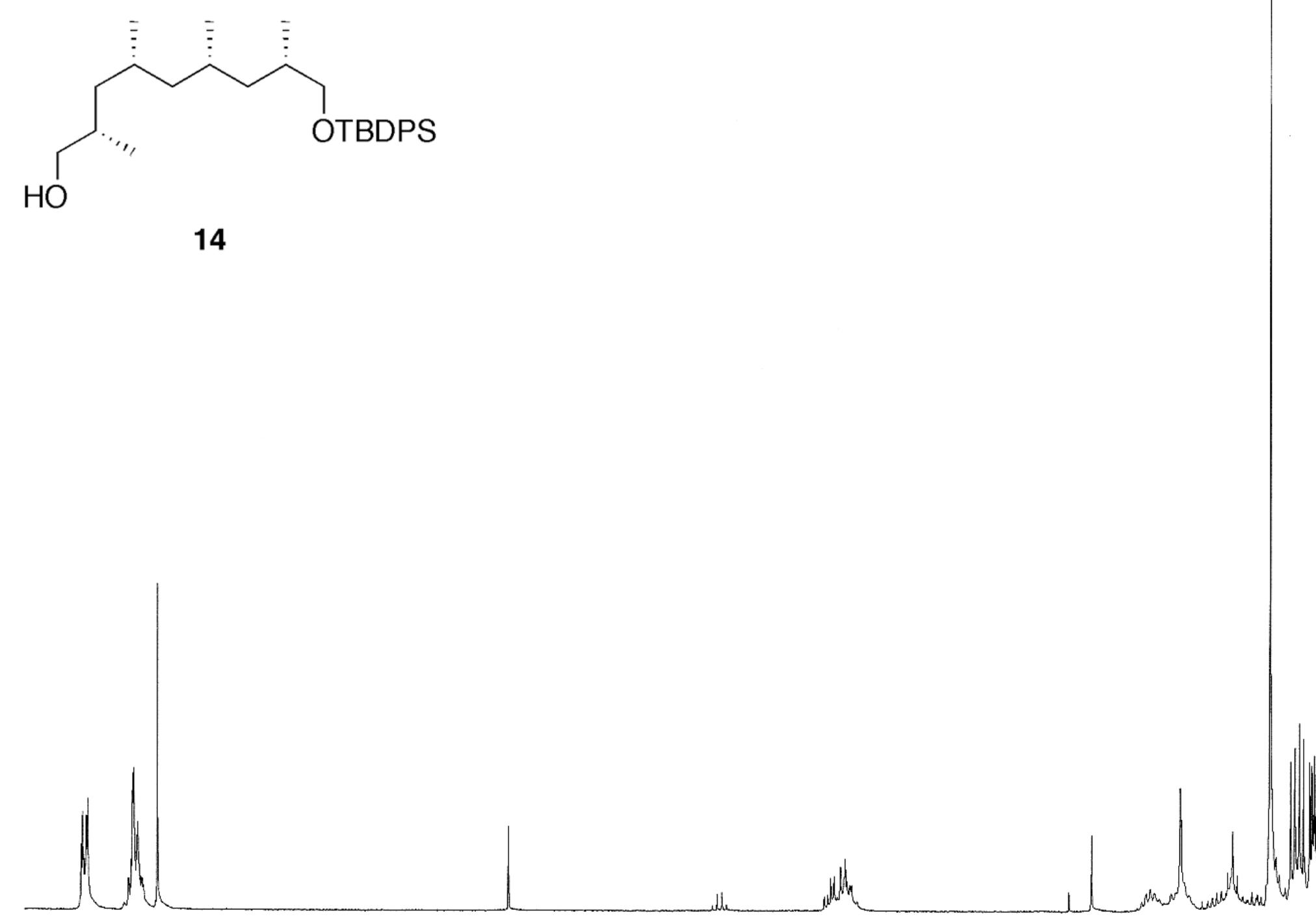

PPM

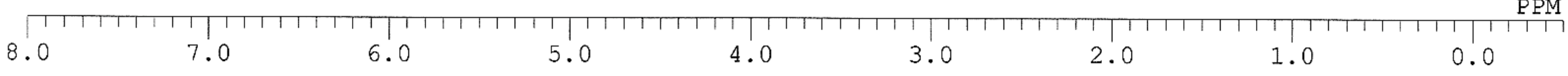



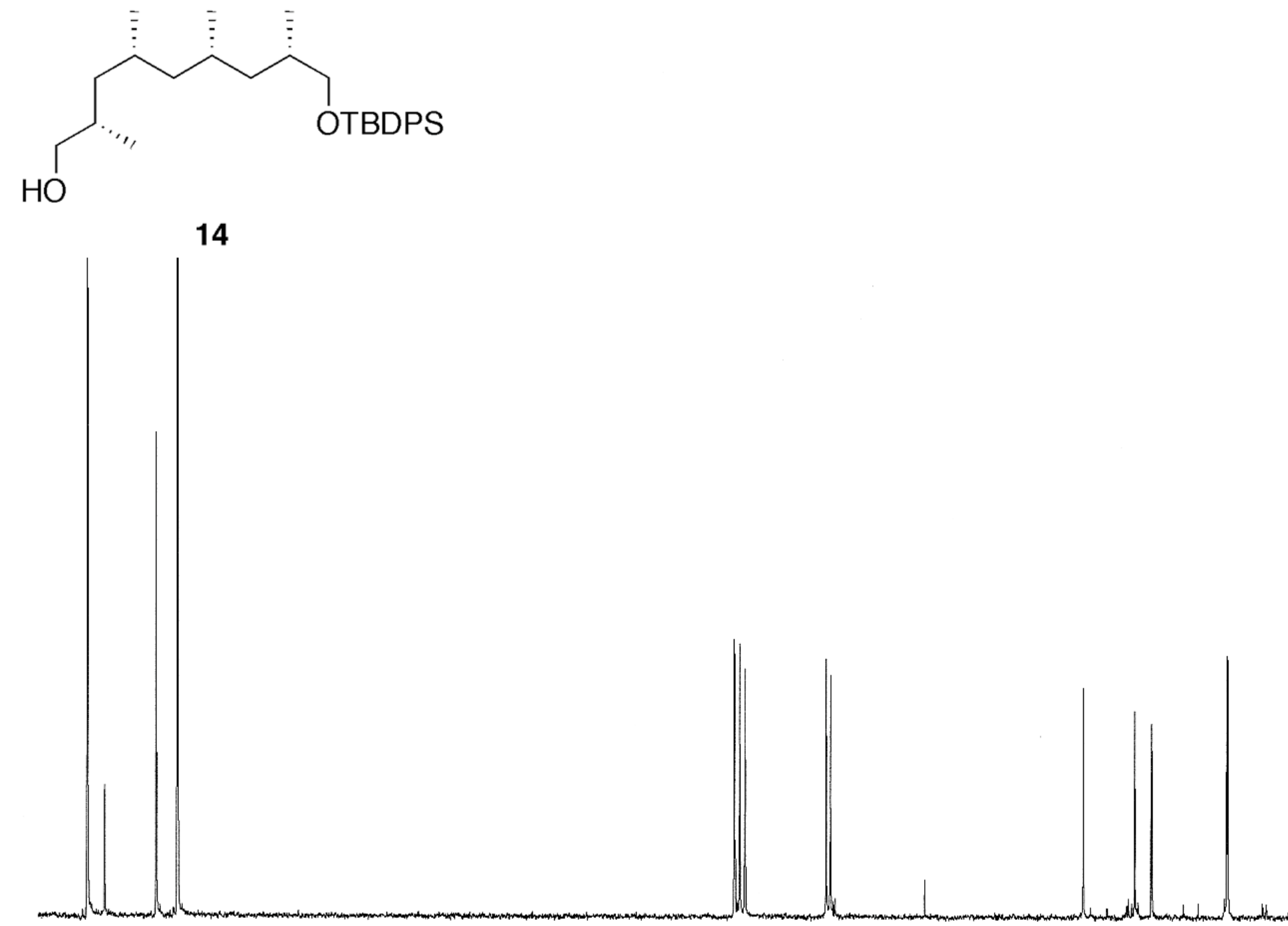

PPM

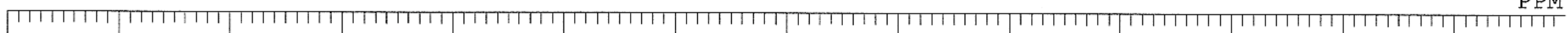
140 .
120.0
$110.0 \quad 100.0$
90.0
80.0
70.0
60.0
50.0
40.0
30.0
20.0
10.0 


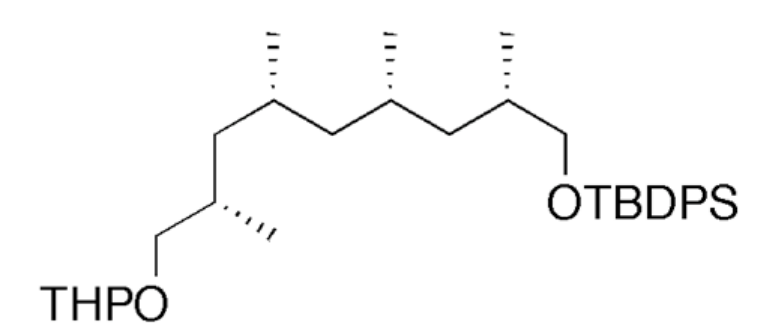

$14 a$

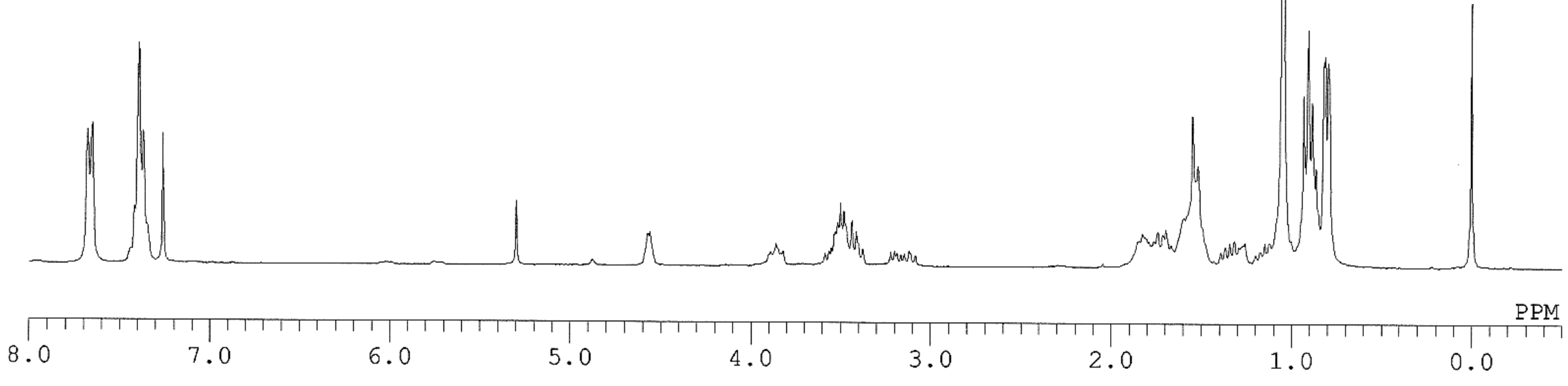

$\mathrm{S}^{\prime}$

17 


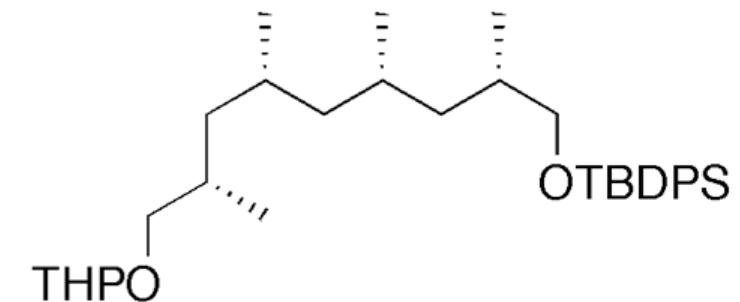

$14 a$
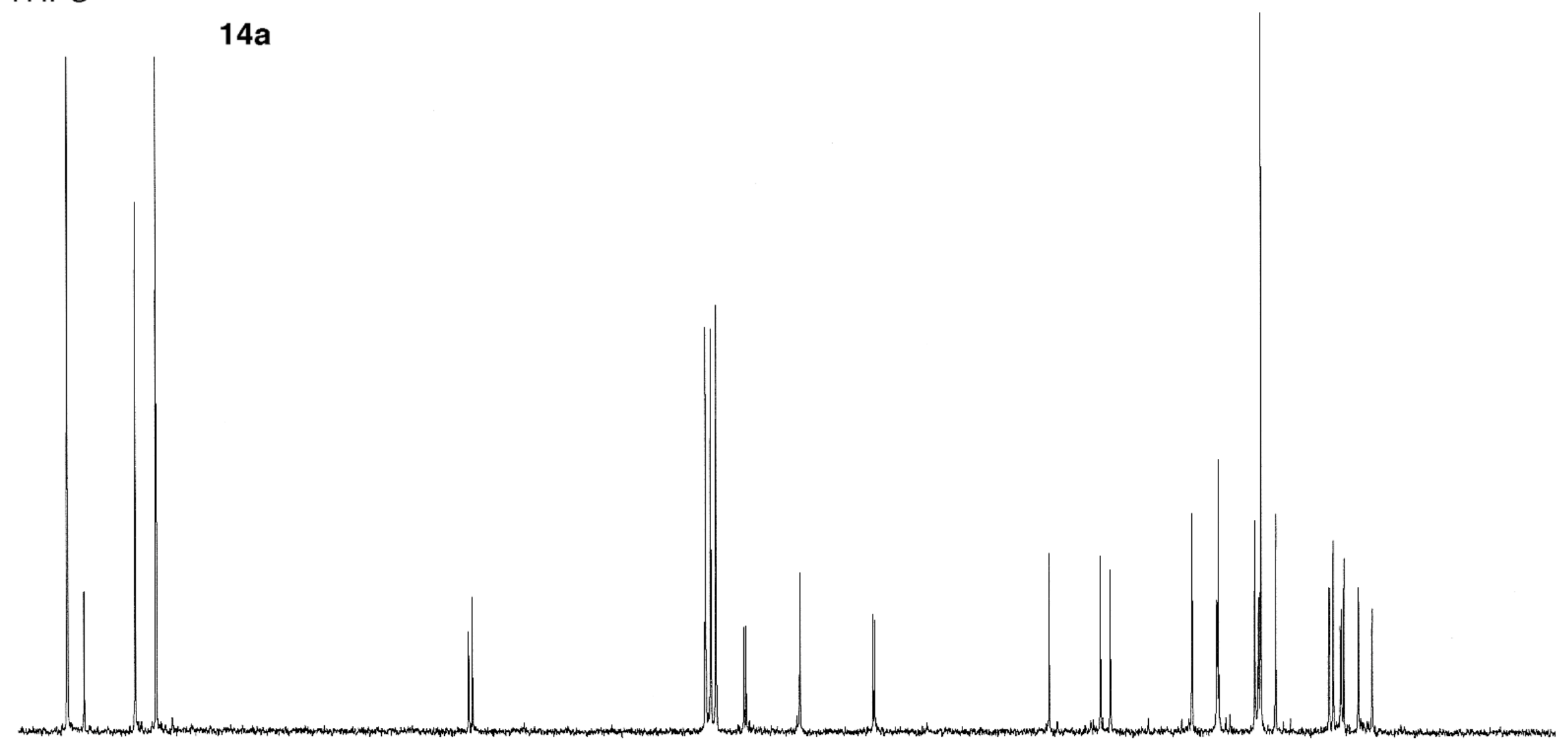

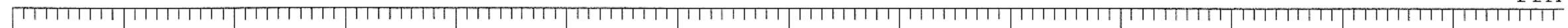

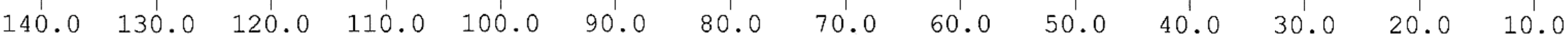




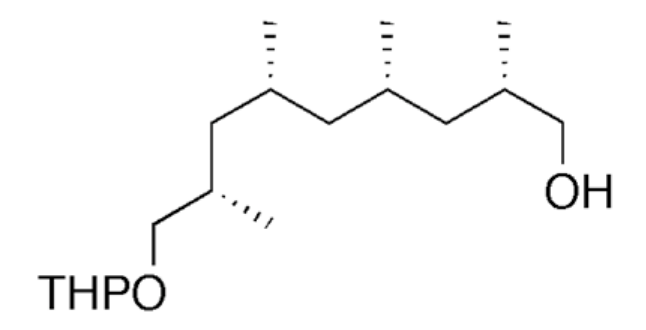

$14 b$

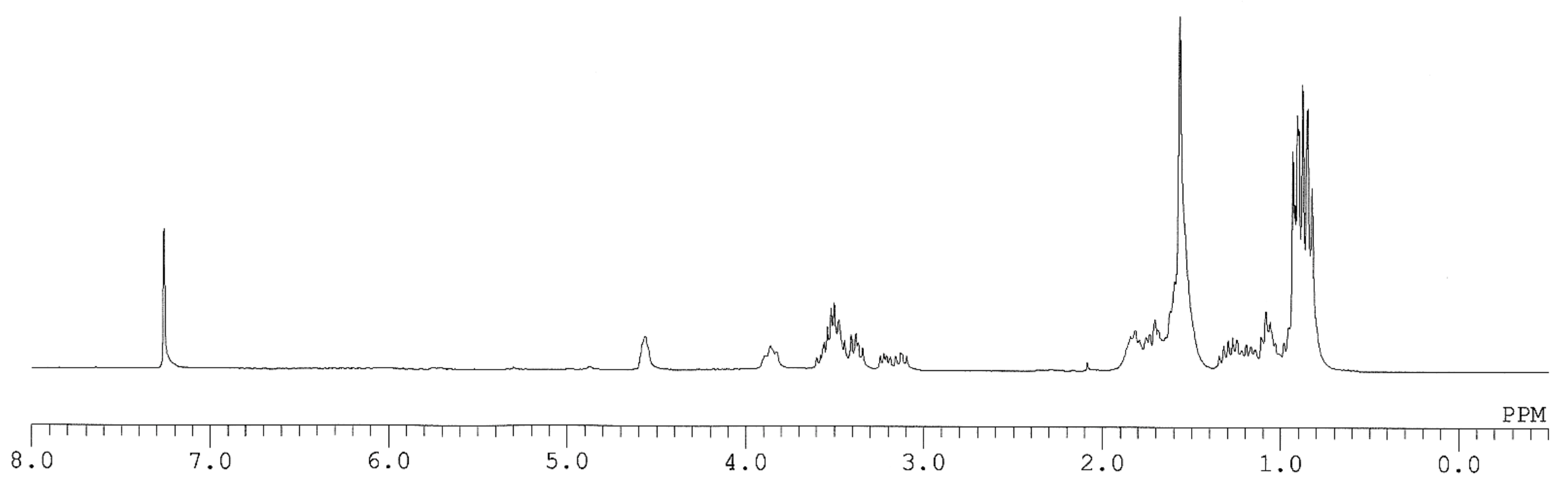




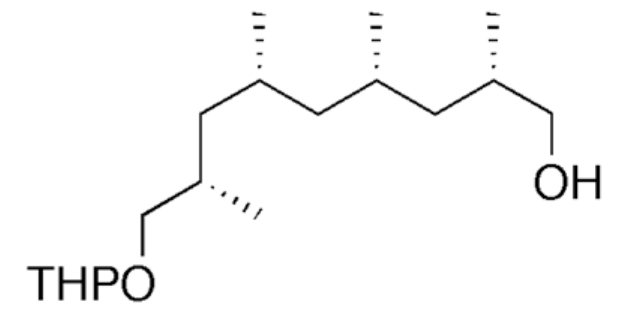

$14 b$

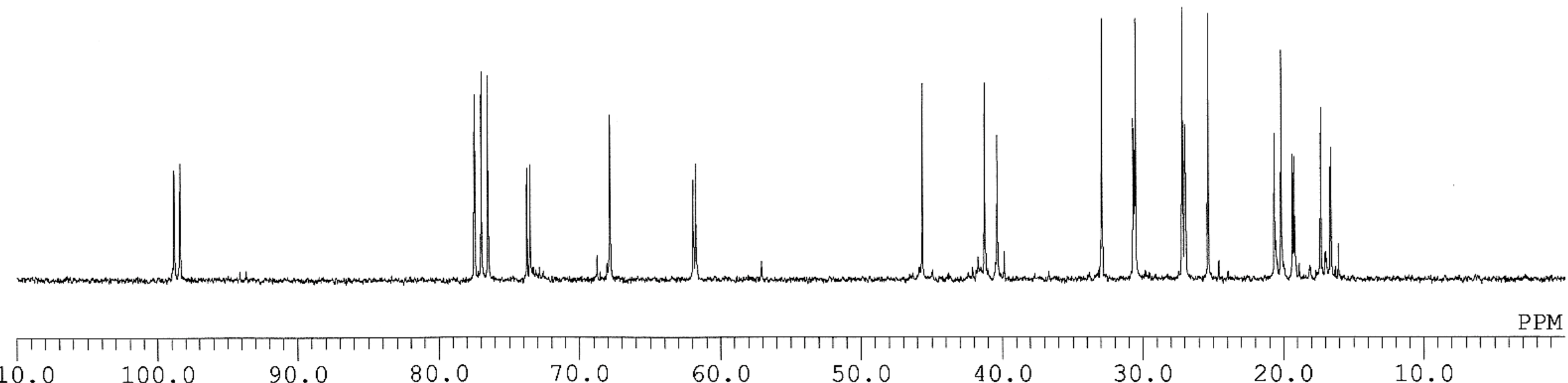
110.0
100.0
90.0
80.0
70.0
60.0
50.0
40.0
30.0
20.0
10.0 


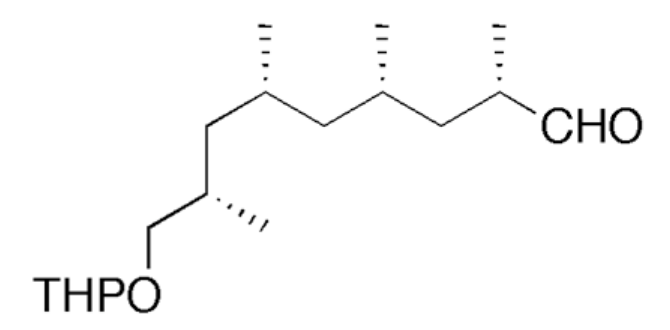

15

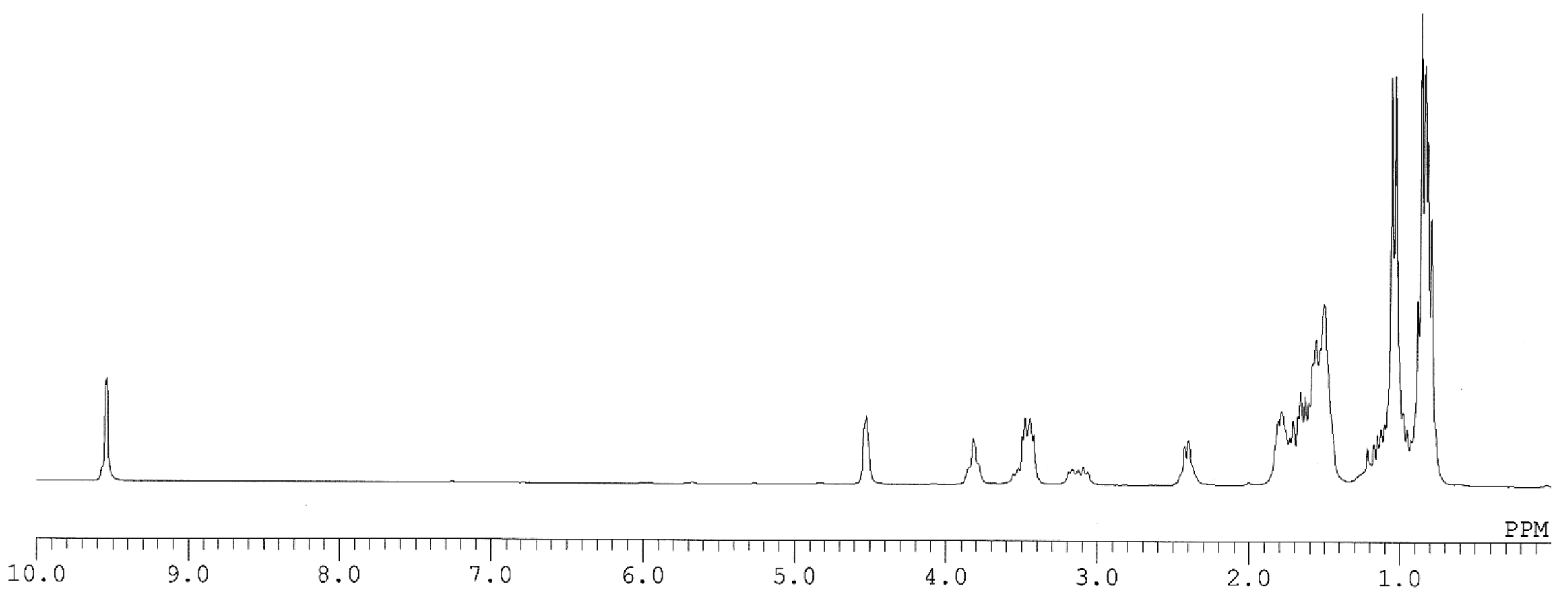




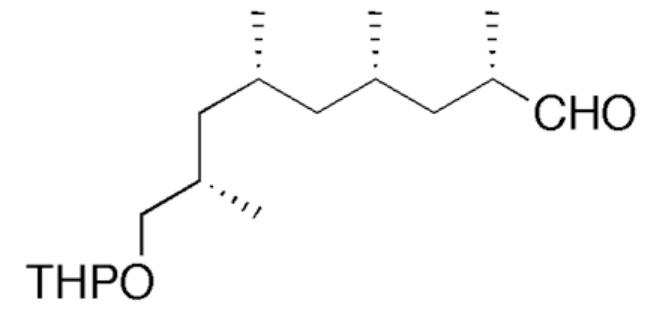

15

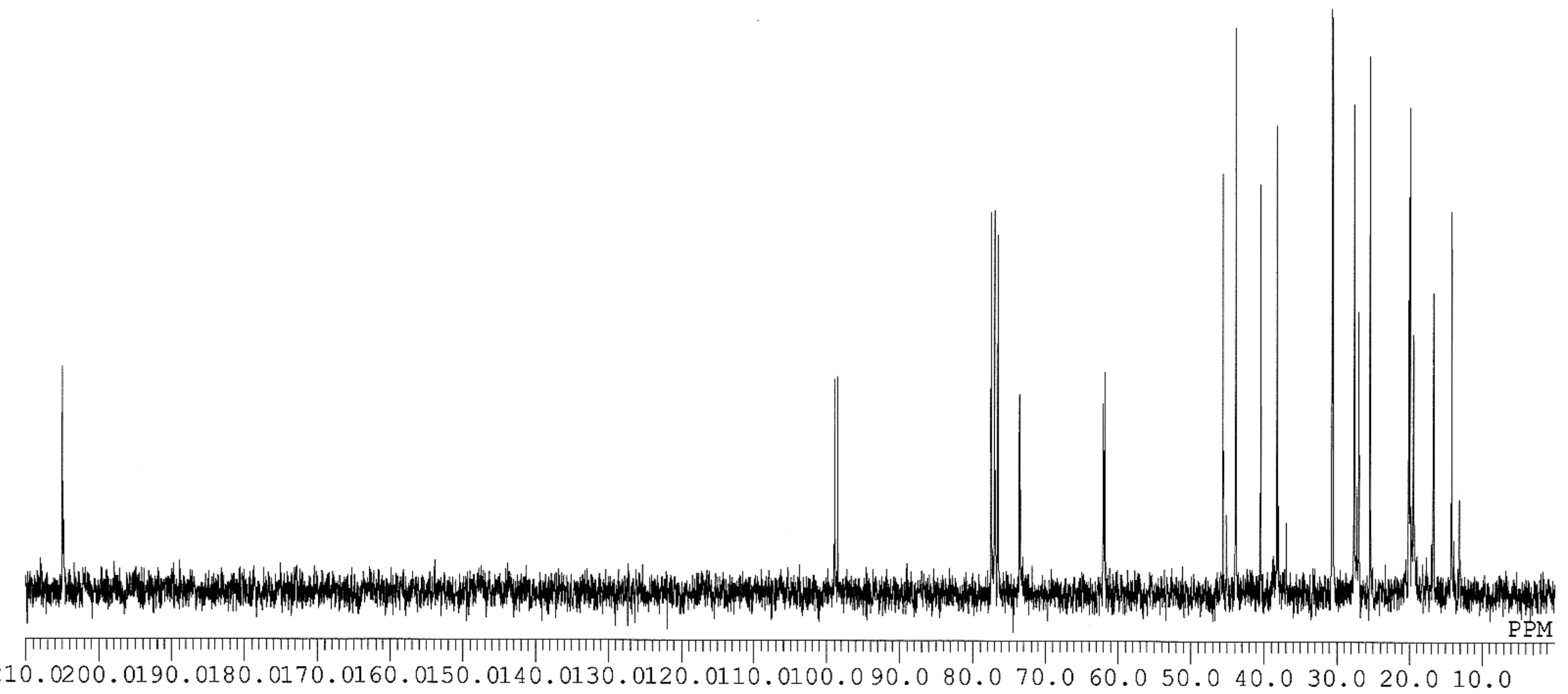




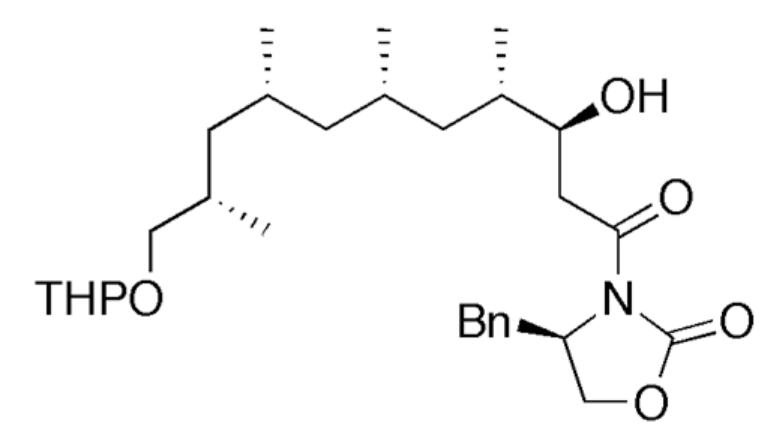

16

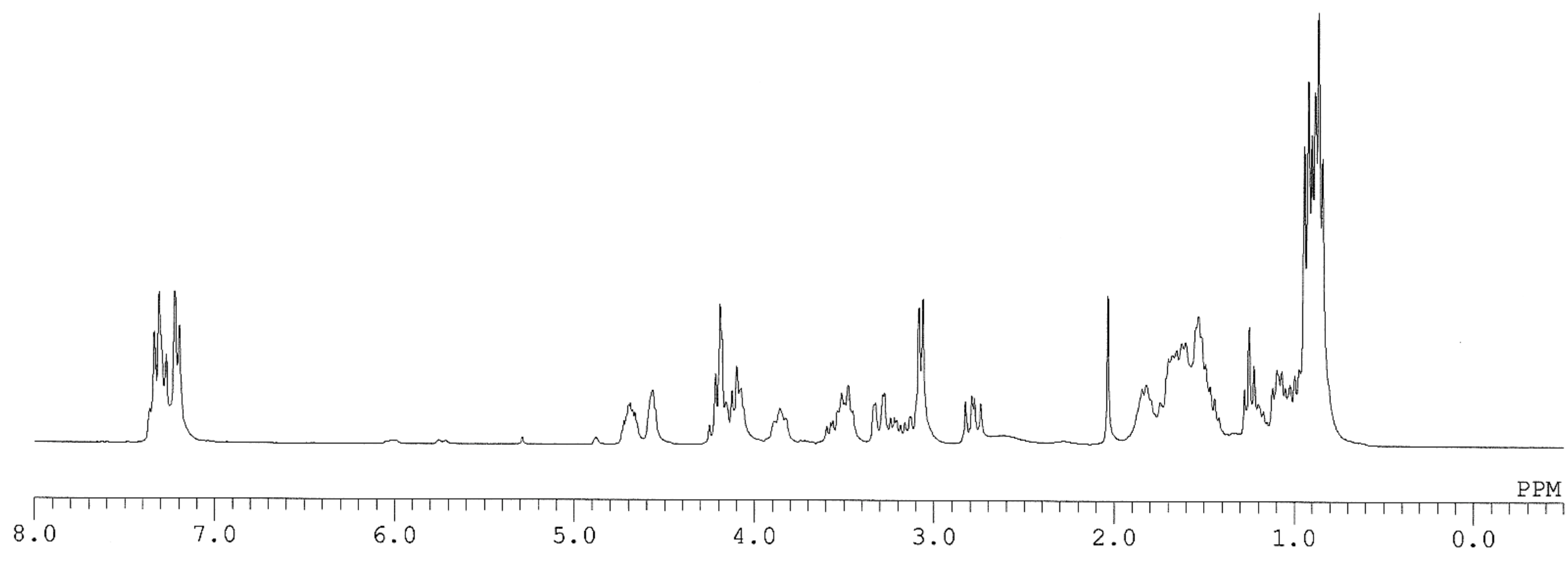




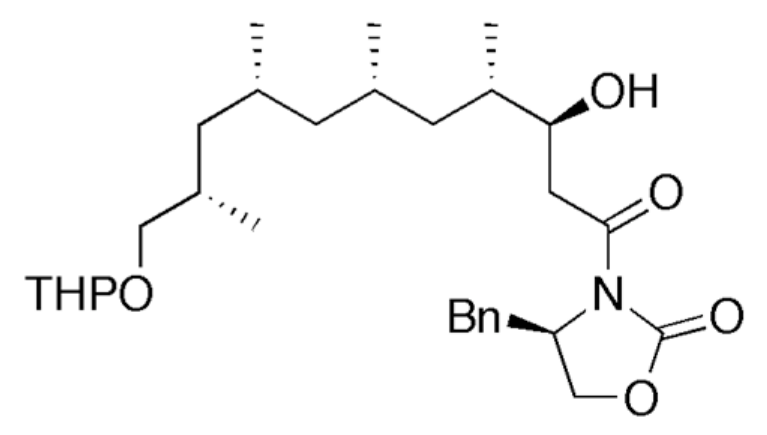

16

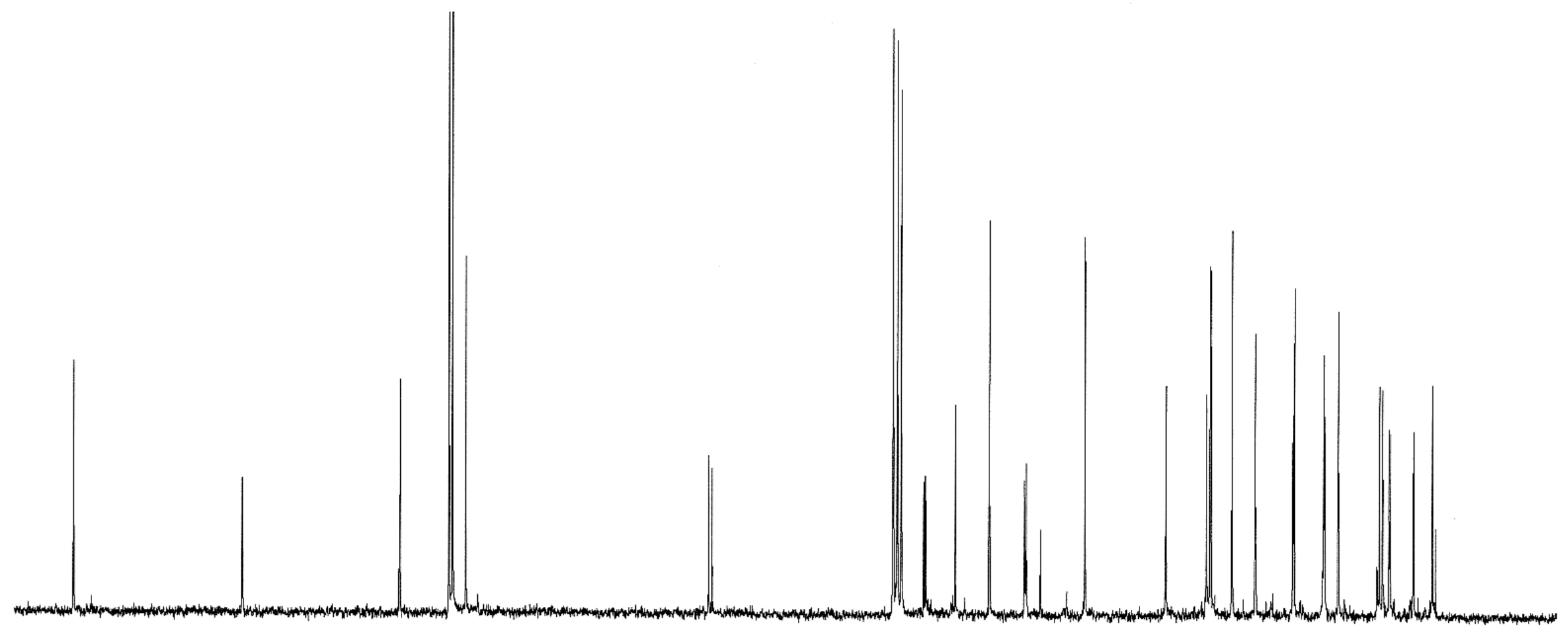

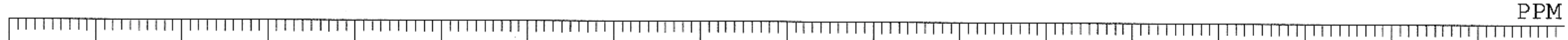
$180.0170 .0160 .0150 .0140 .0130 .0120 .0110 .0100 .0 \quad 90.0 \quad 80.0 \quad 70.0 \quad 60.0 \quad 50.0 \quad 40.0 \quad 30.0 \quad 20.0 \quad 10.0$ 


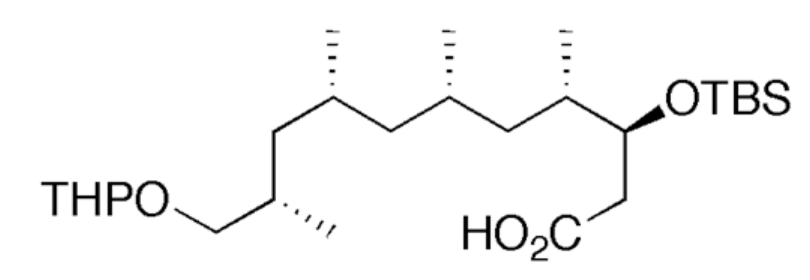

3

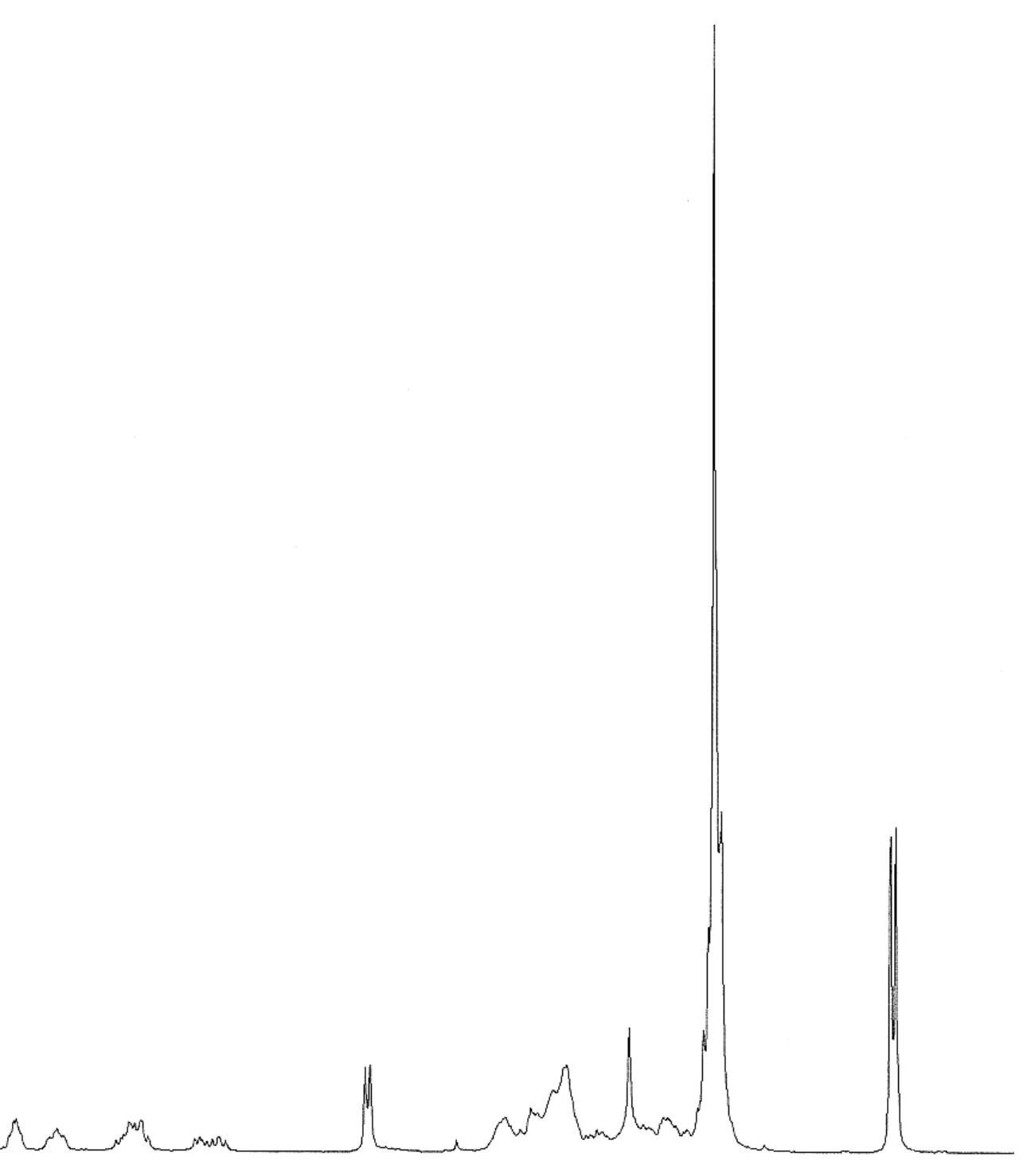

PPM

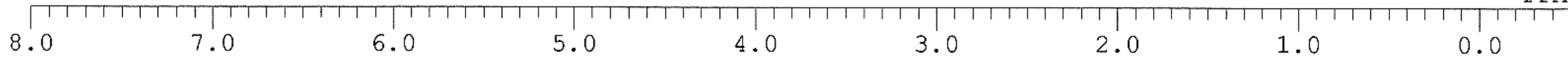

$\mathrm{S}^{\prime}$ 


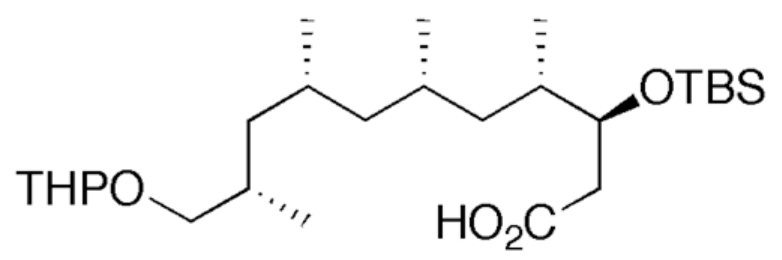

3

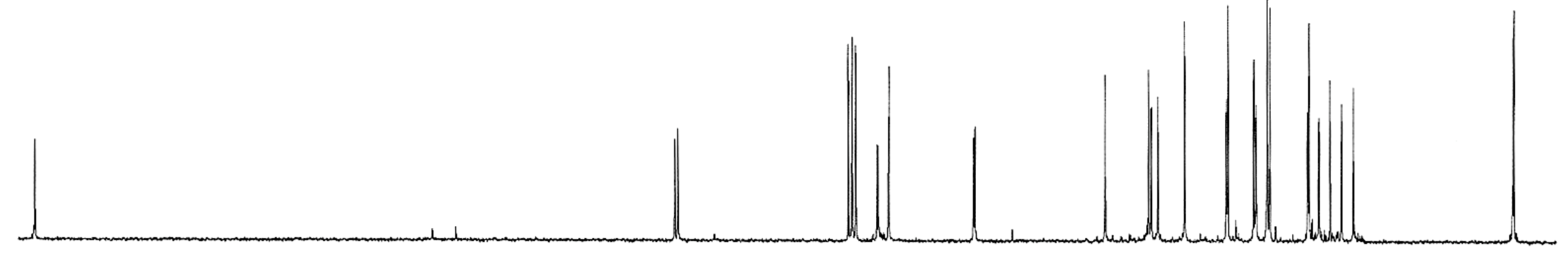

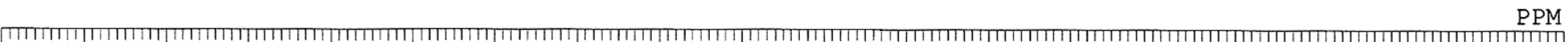

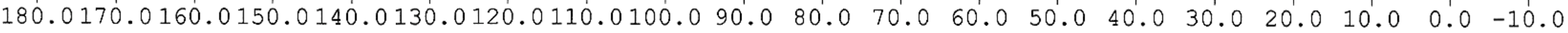




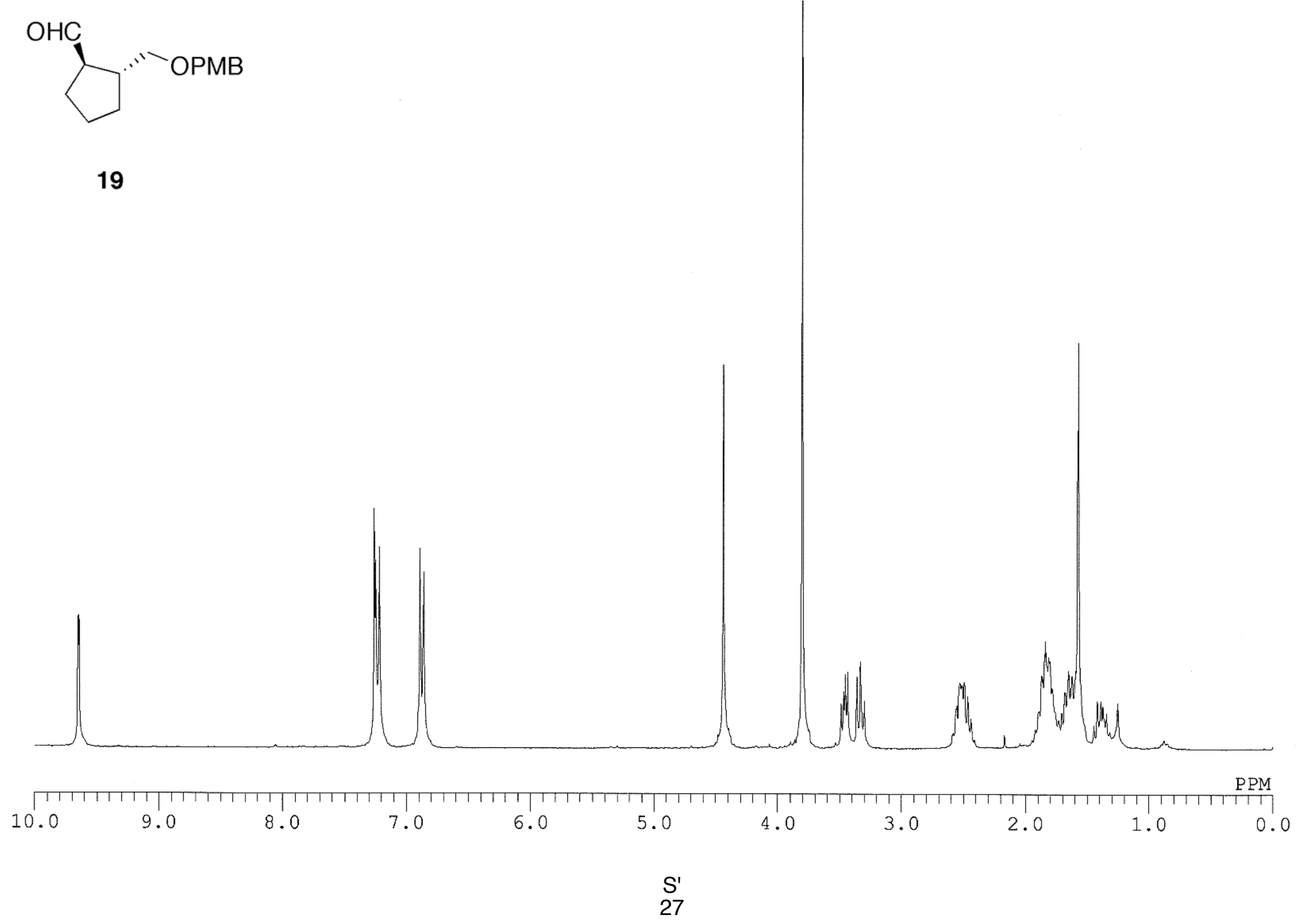




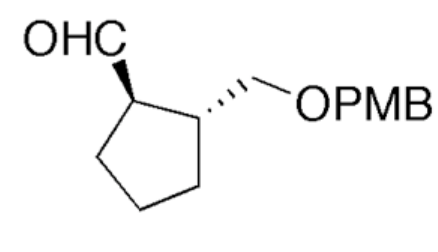

19

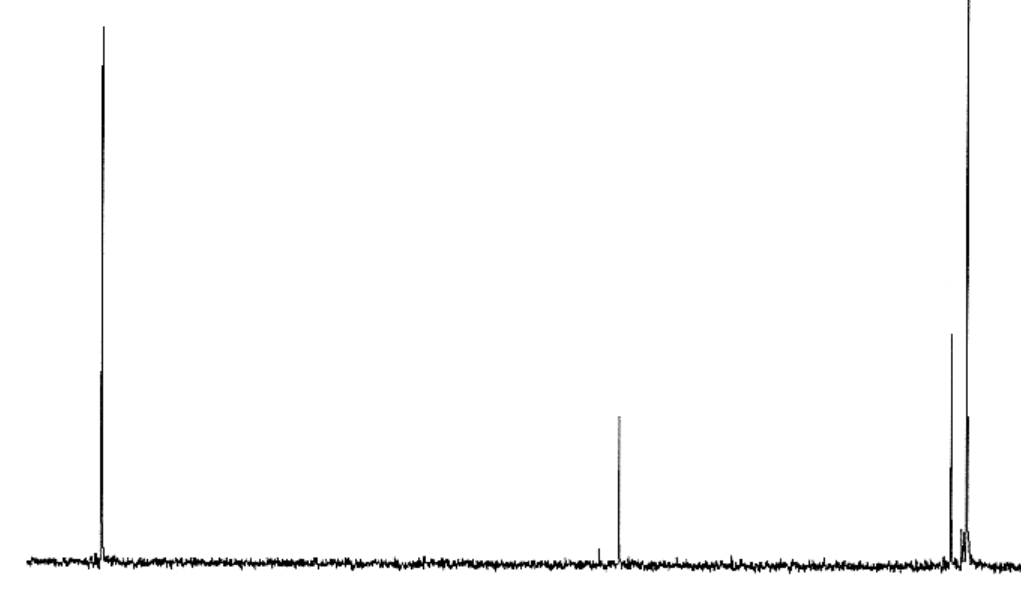

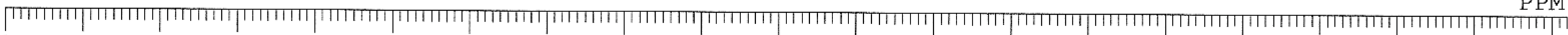
$210.0200 .0190 .0180 .0170 .0160 .0150 .0140 .0130 .0120 .0110 .0100 .090 .0 \quad 80.0 \quad 70.0 \quad 60.0 \quad 50.0 \quad 40.0 \quad 30.0 \quad 20.0 \quad 10.0$ 

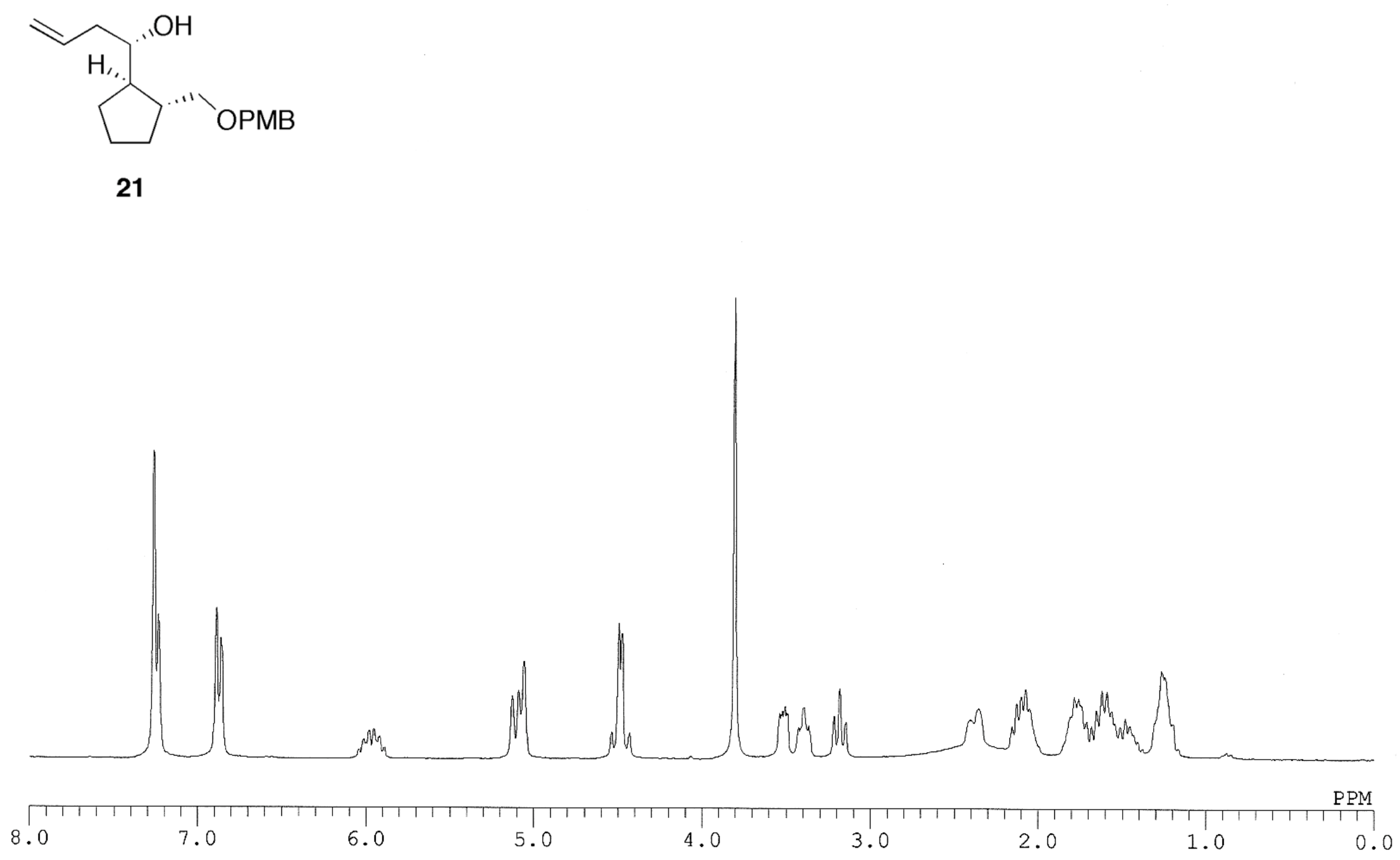


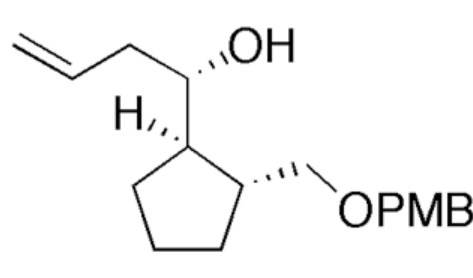

21

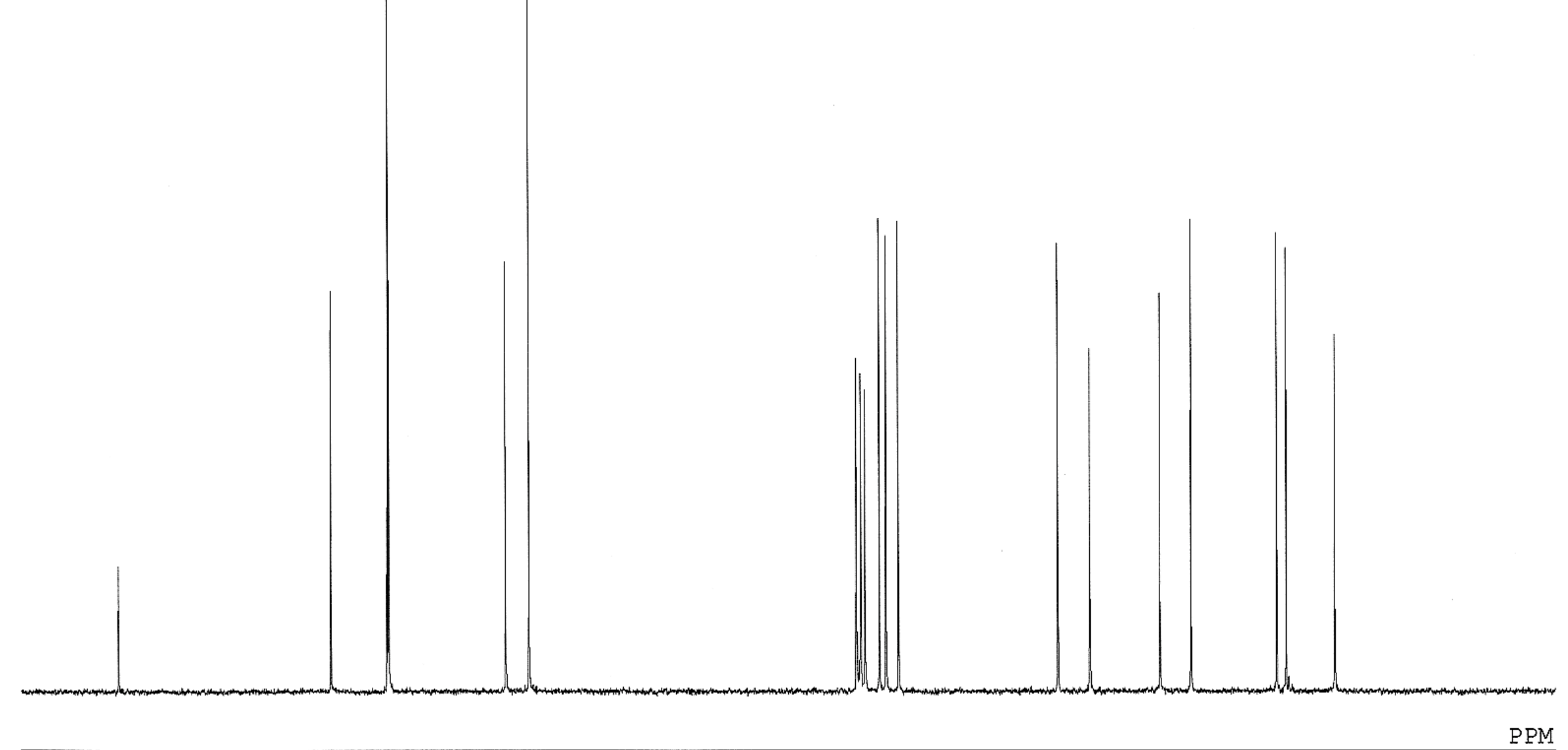

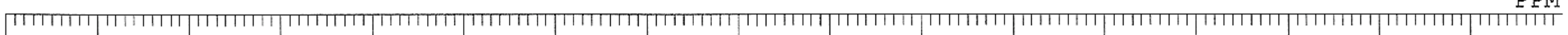

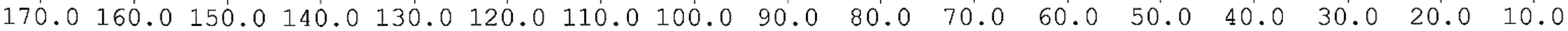




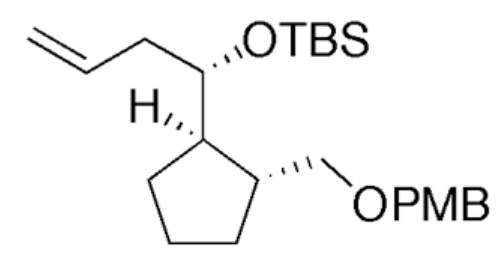

25

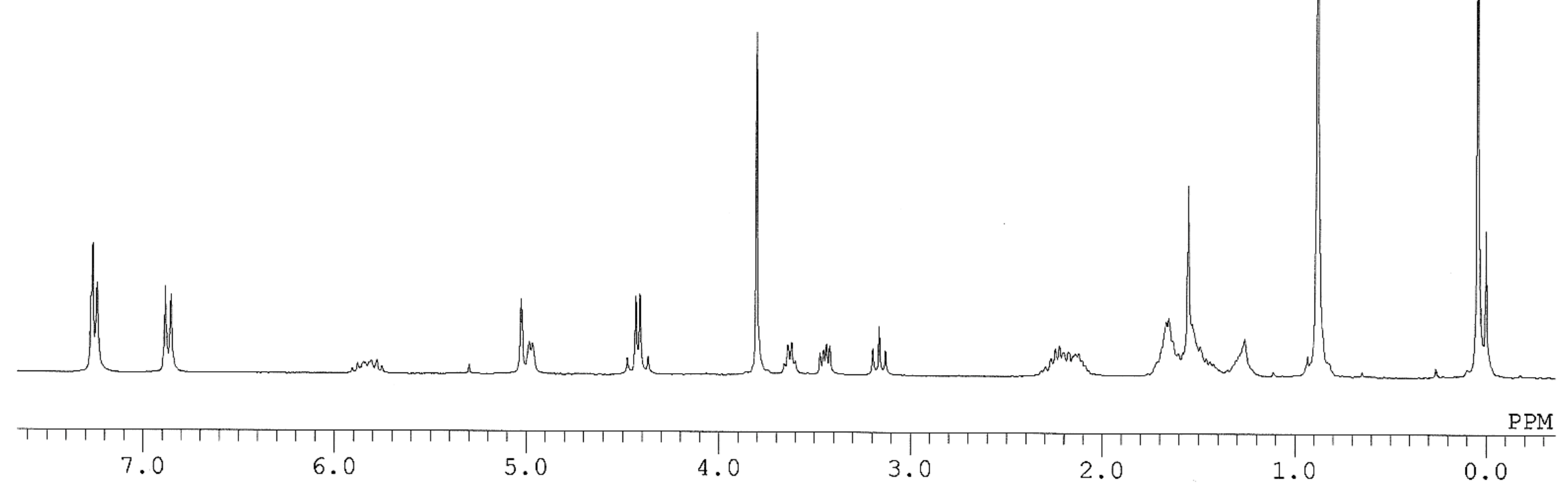




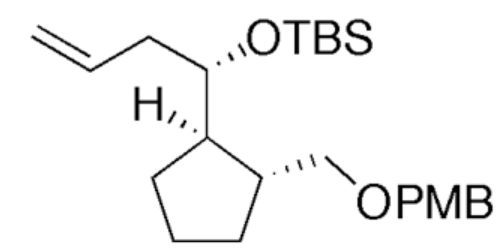

25

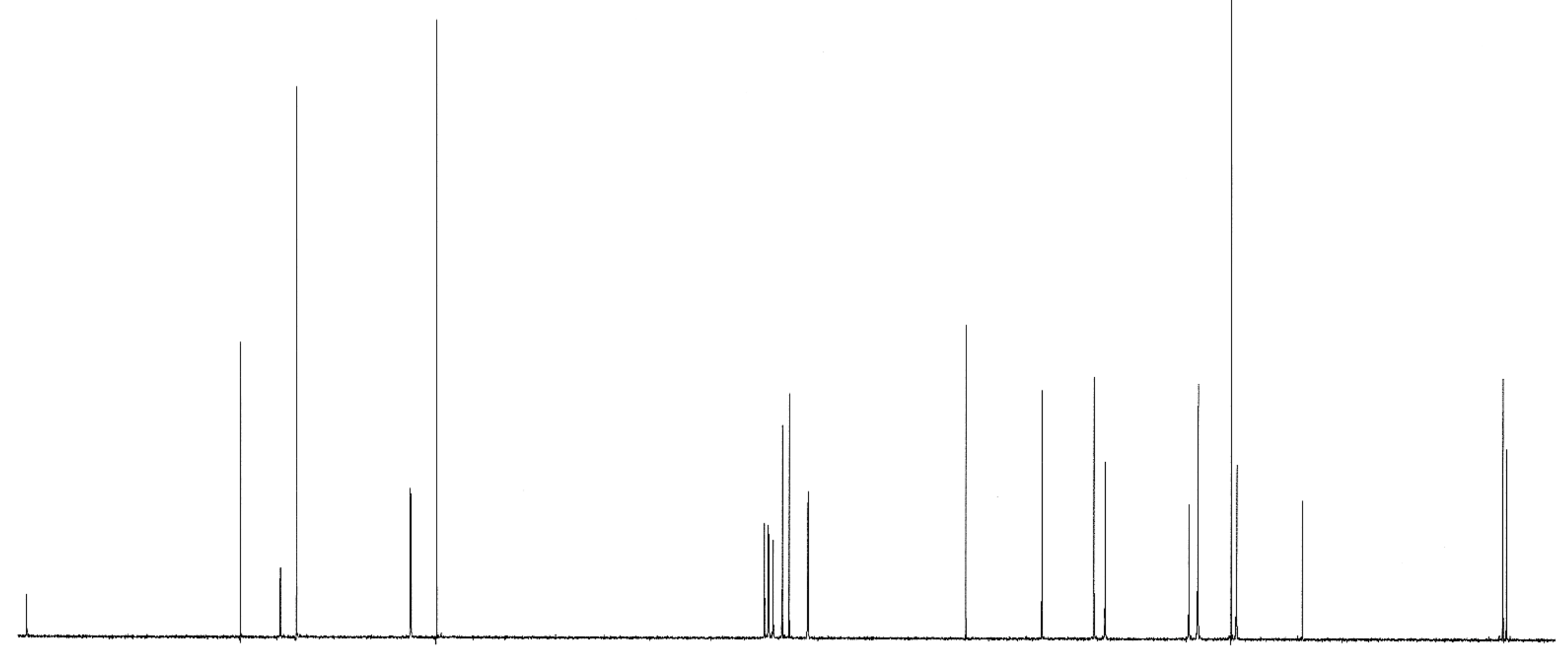

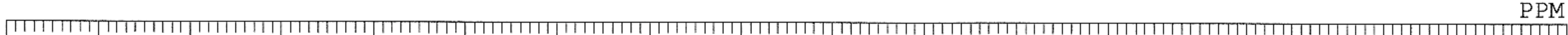
$\begin{array}{llllllllllllllllll}160.0 & 150.0 & 140.0 & 130.0 & 120.0 & 110.0 & 100.0 & 90.0 & 80.0 & 70.0 & 60.0 & 50.0 & 40.0 & 30.0 & 20.0 & 10.0 & 0.0 & -10.0\end{array}$ 


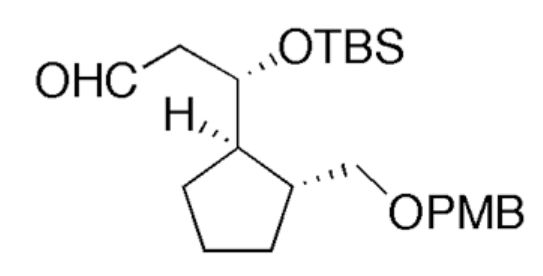

26

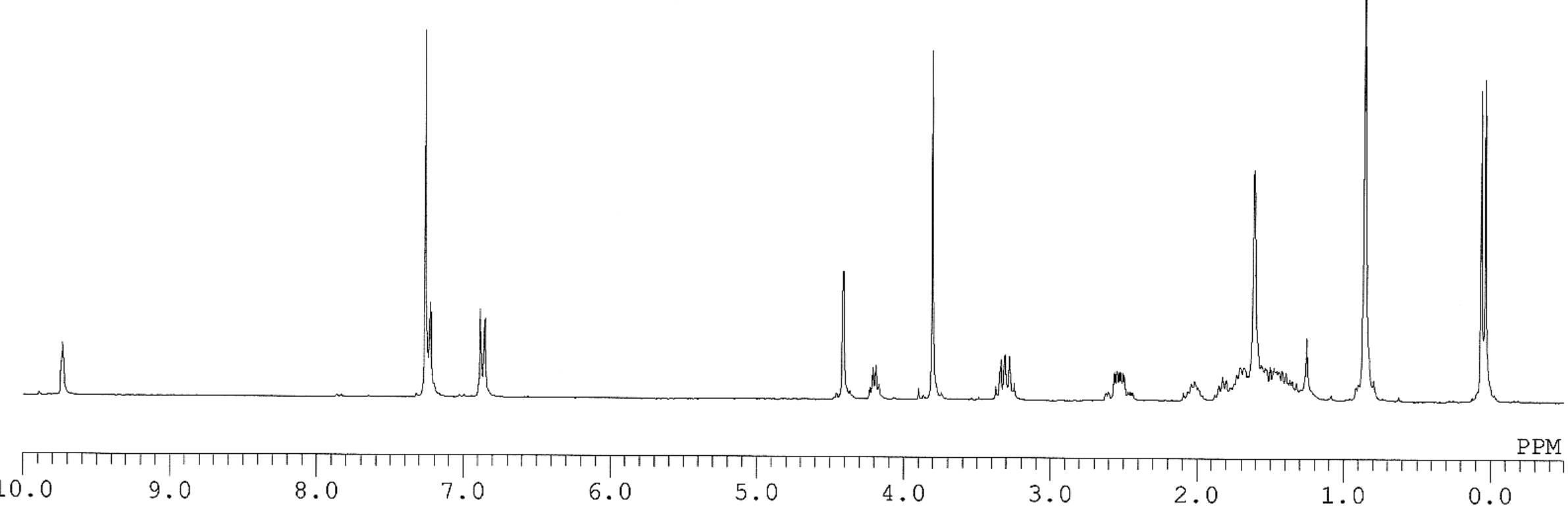




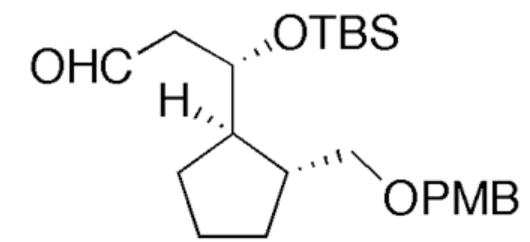

26

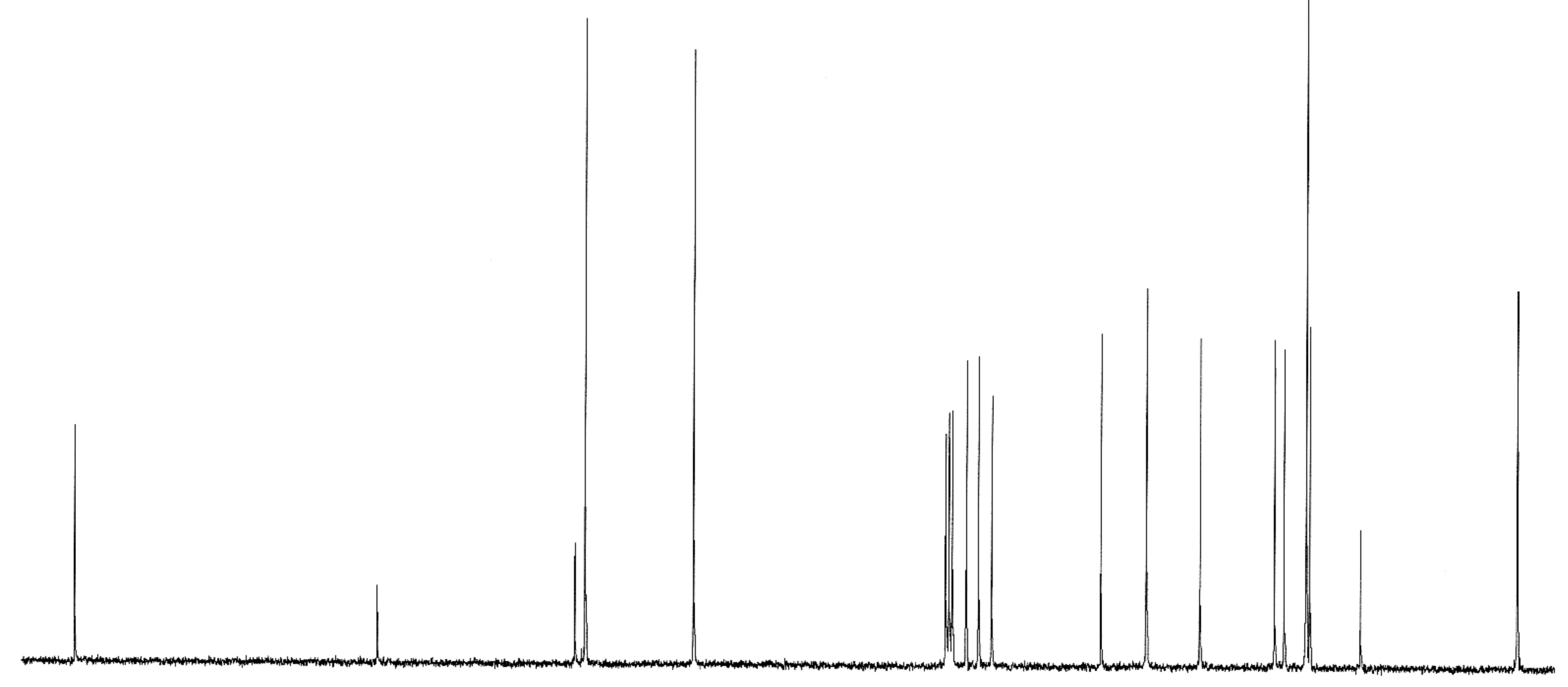

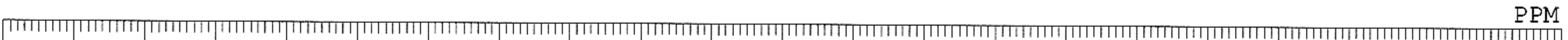
$210.0200 .0190 .0180 .0170 .0160 .0150 .0140 .0130 .0120 .0110 .0100 .090 .080 .070 .060 .050 .040 .030 .020 .010 .00 .0-10.0$ 

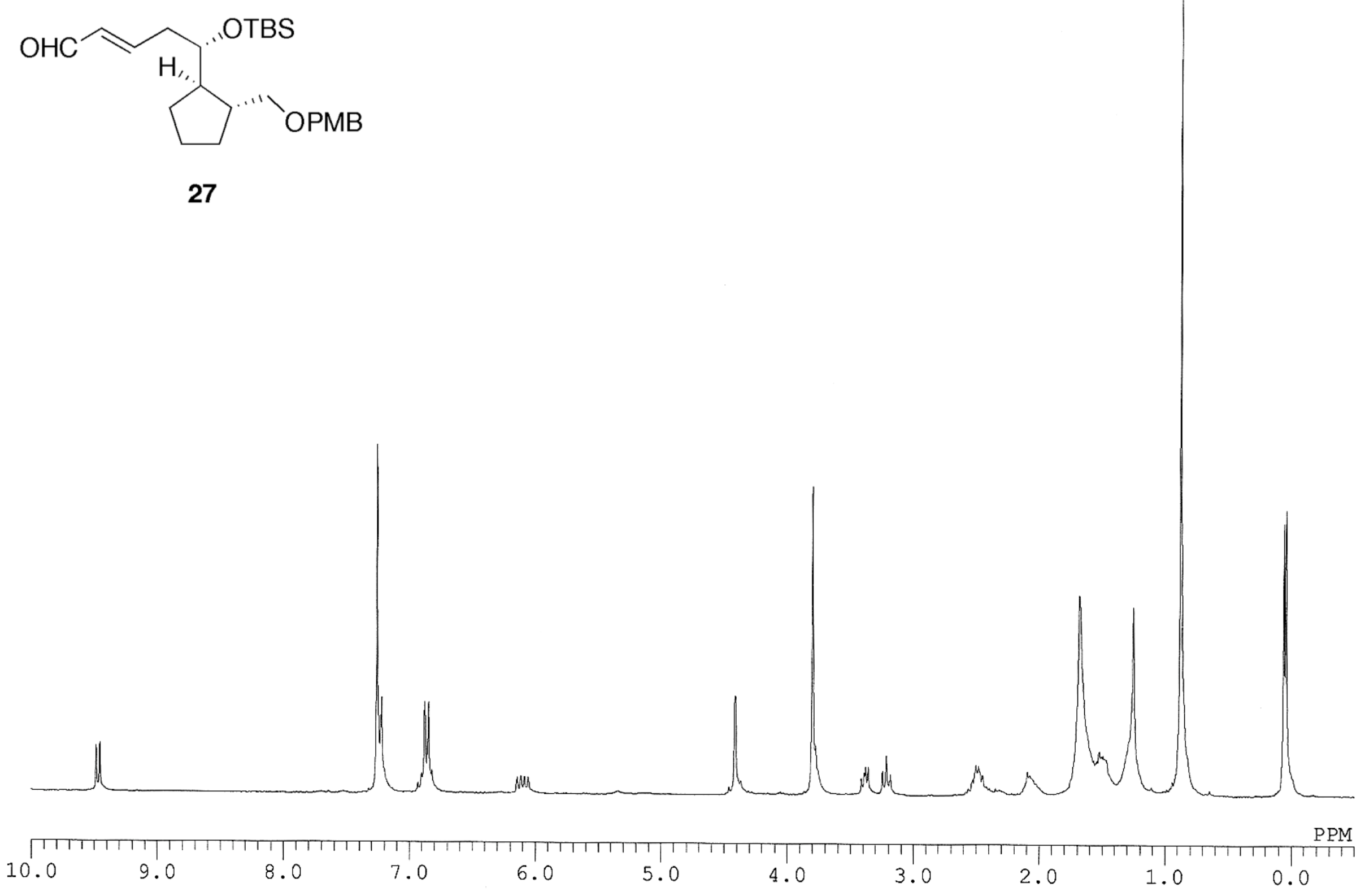


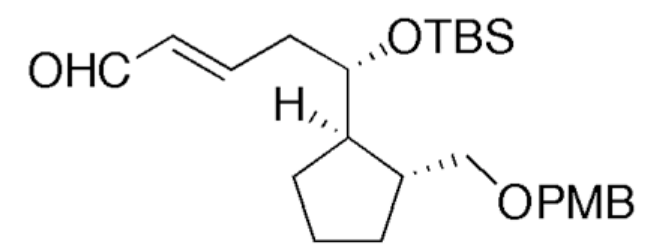

27

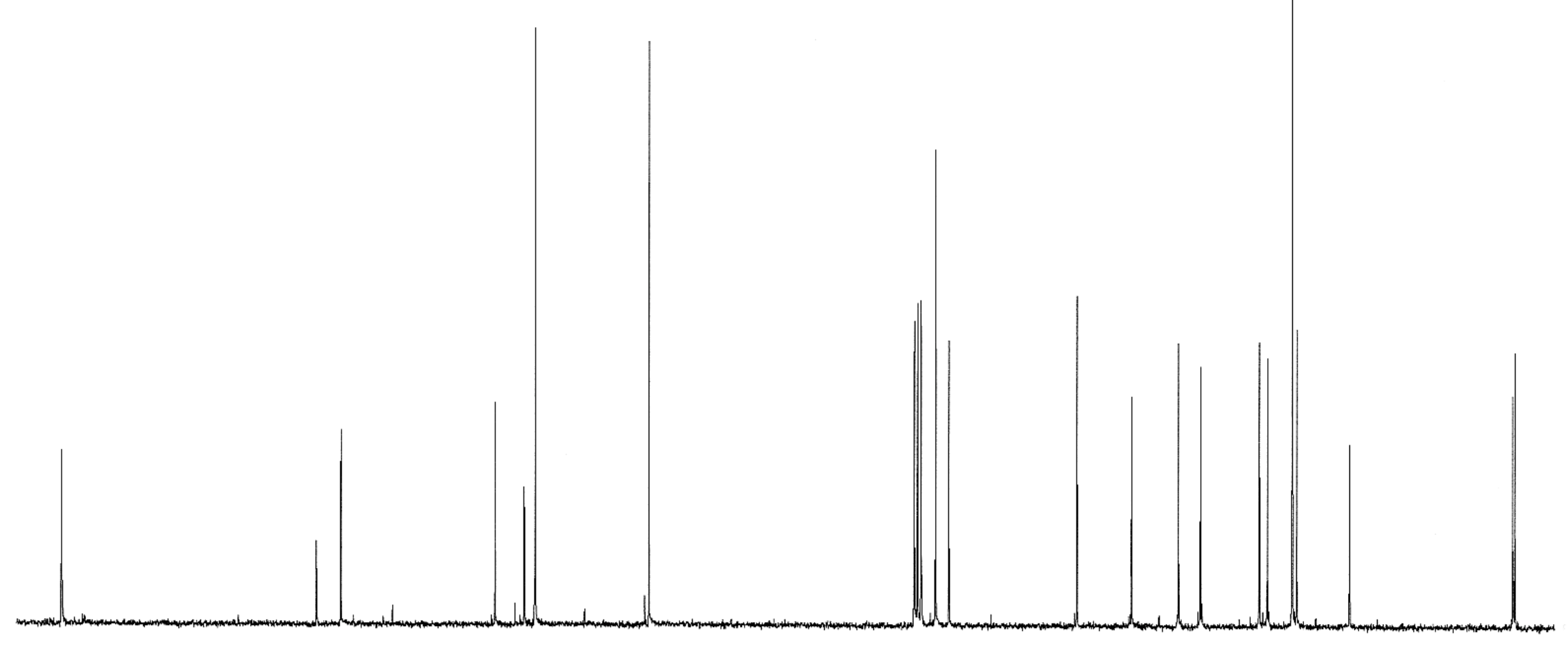

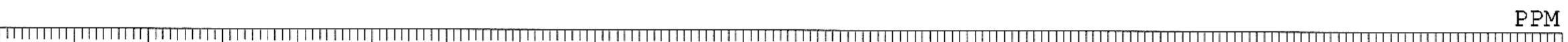
$200.0190 .0180 .0170 .0160 .0150 .0140 .0130 .0120 .0110 .0100 .090 .080 .070 .060 .050 .040 .030 .020 .010 .0 \quad 0.0-10.0$ 


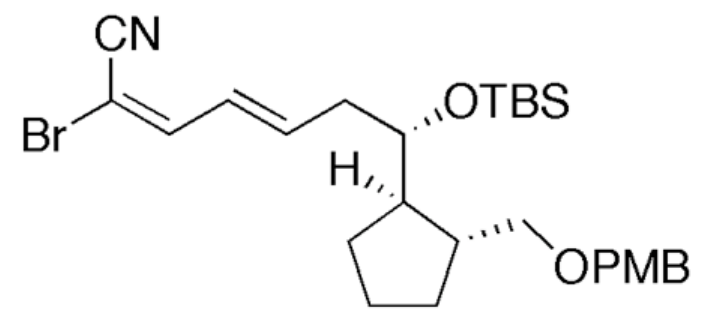

28

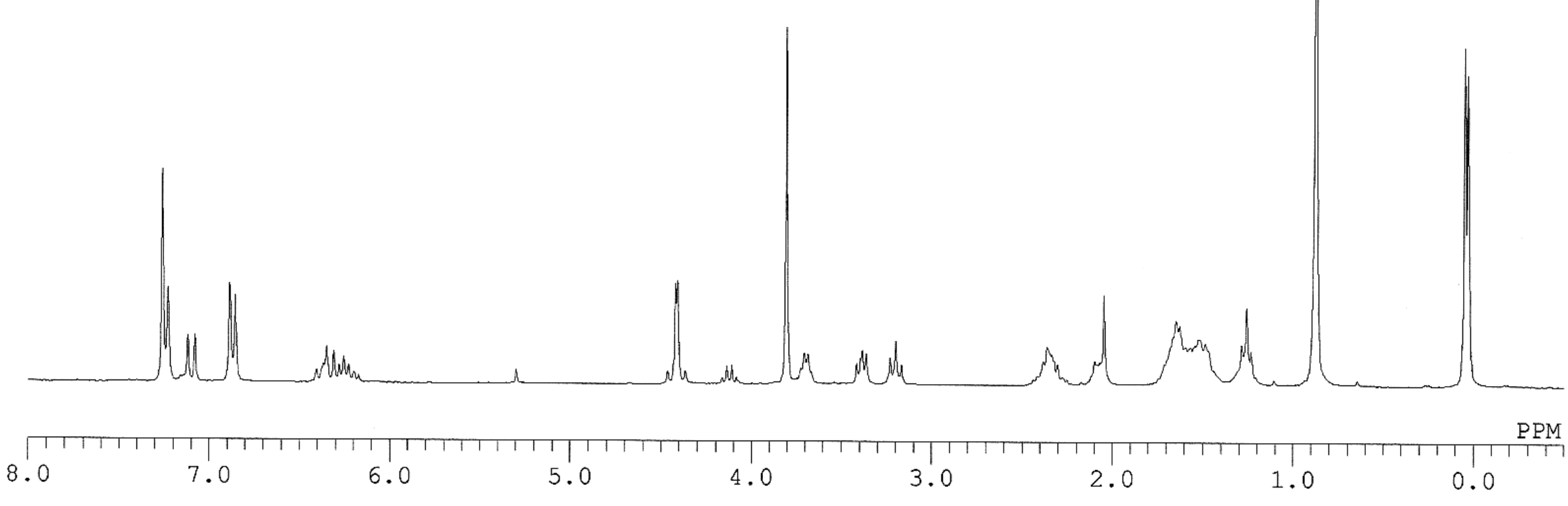




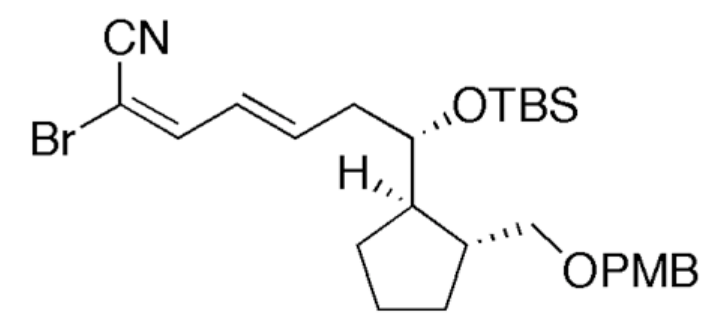

28

How

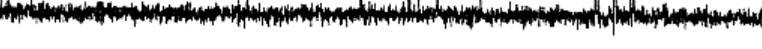

PPM (1)

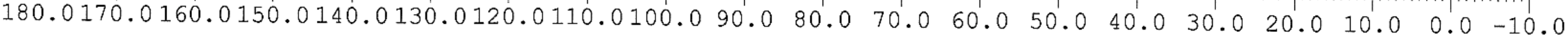




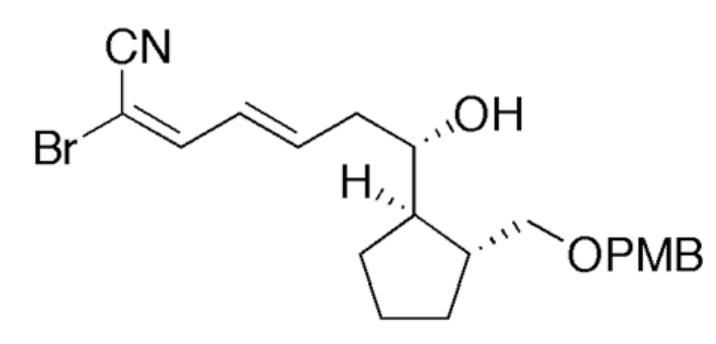

4

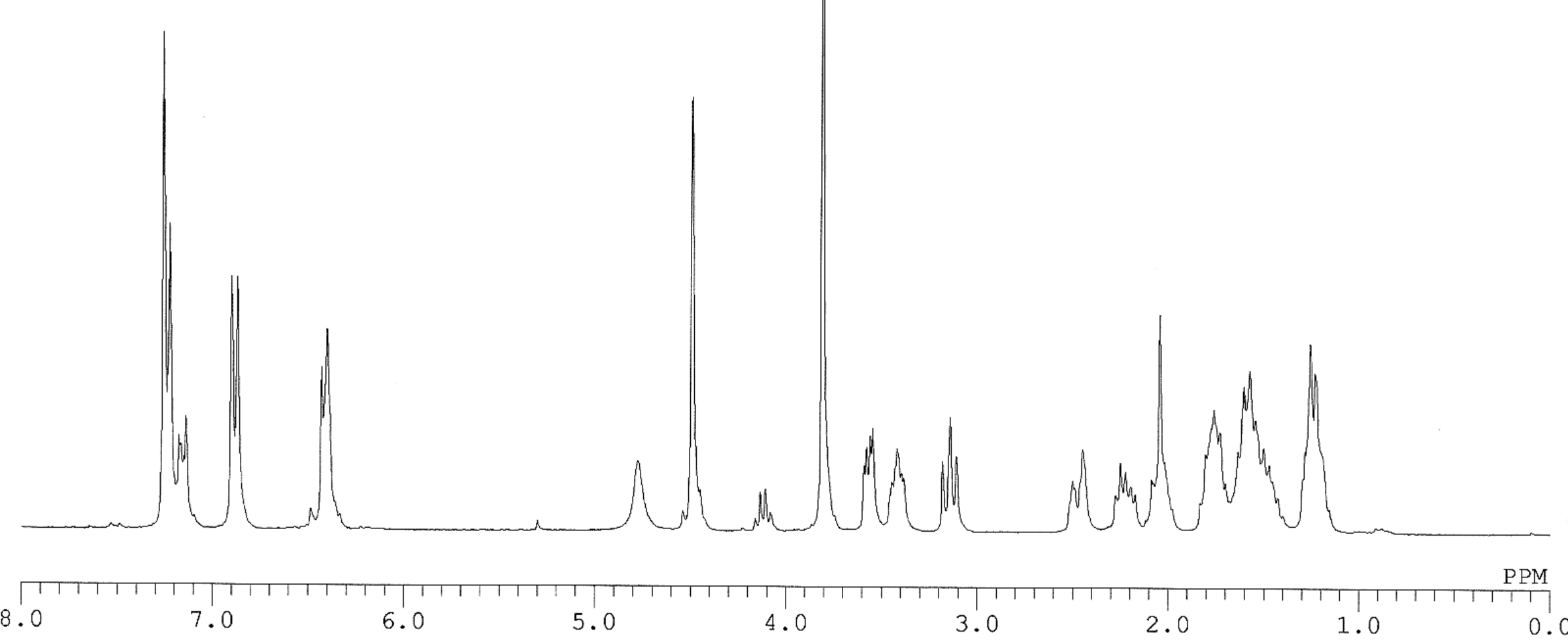




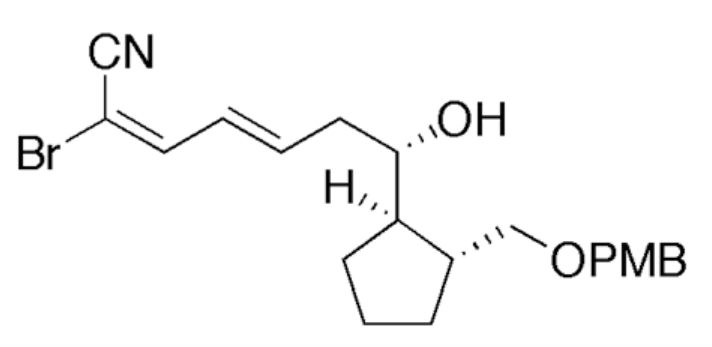

4

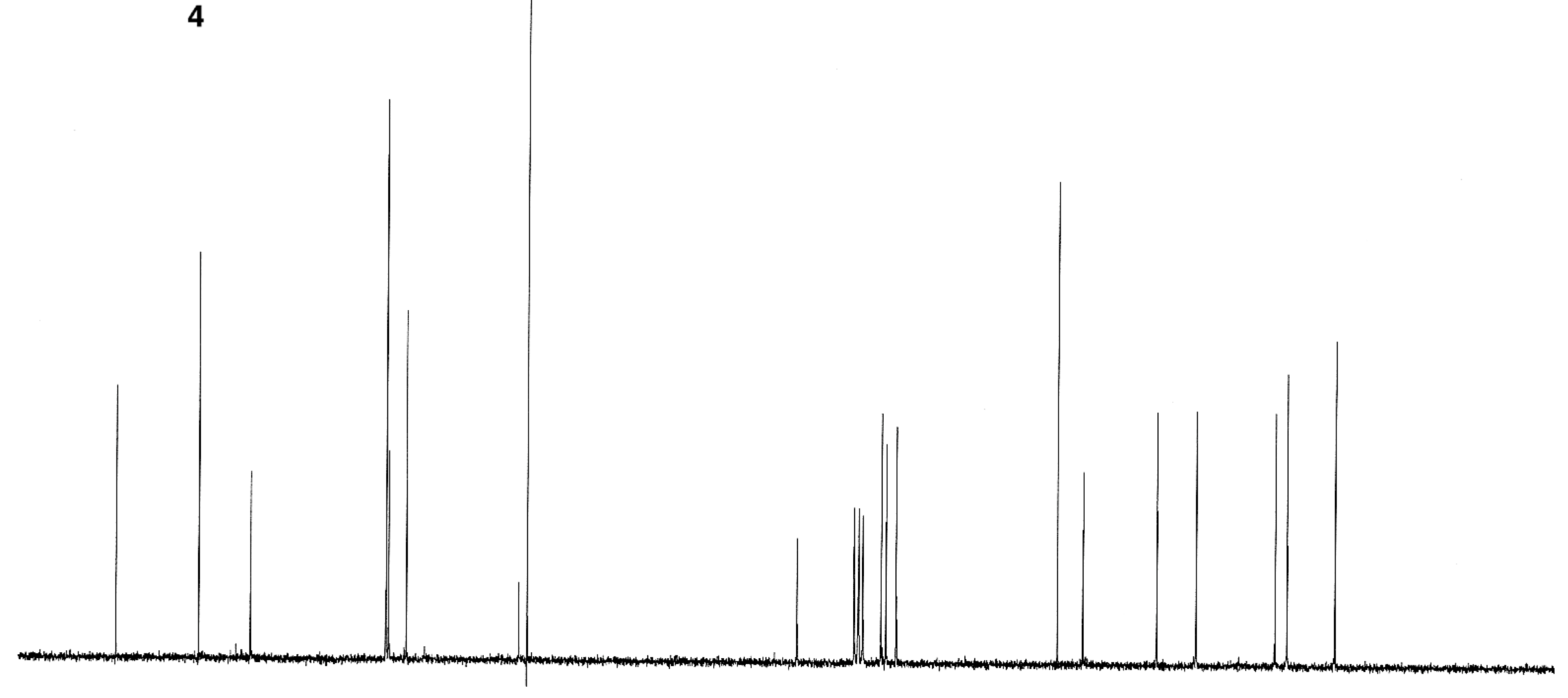

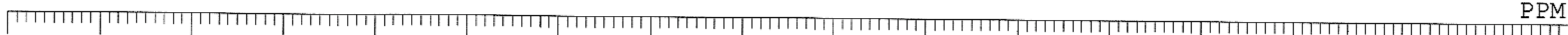

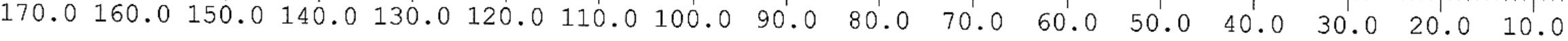




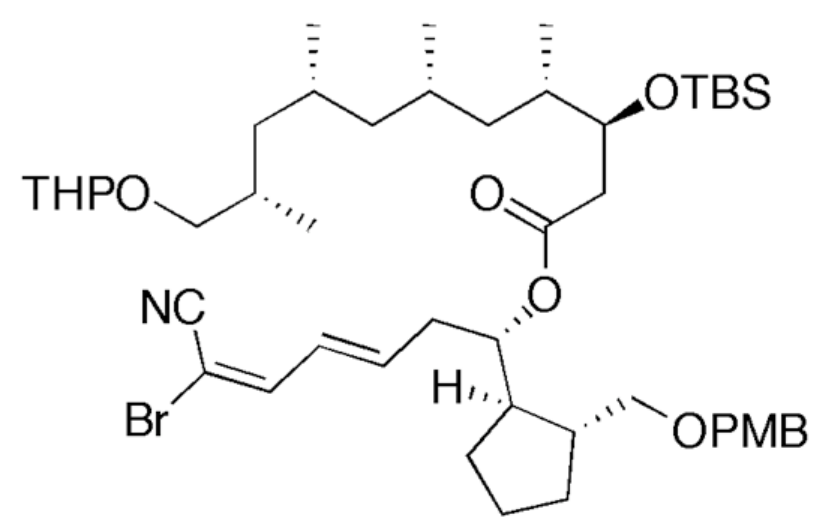

32

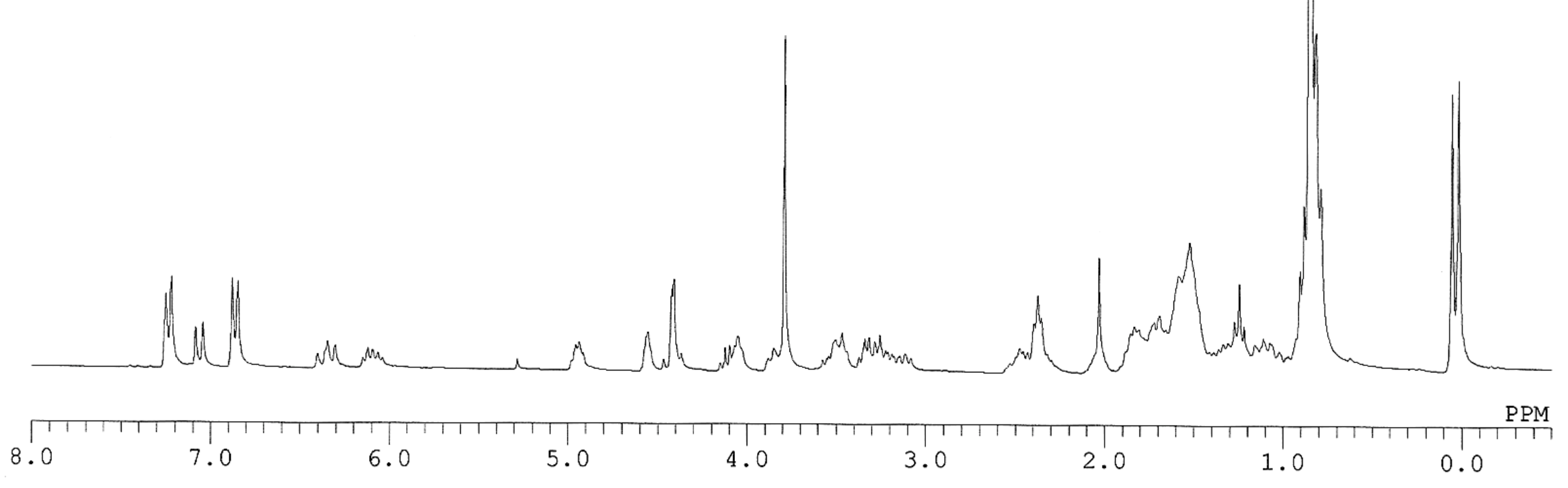




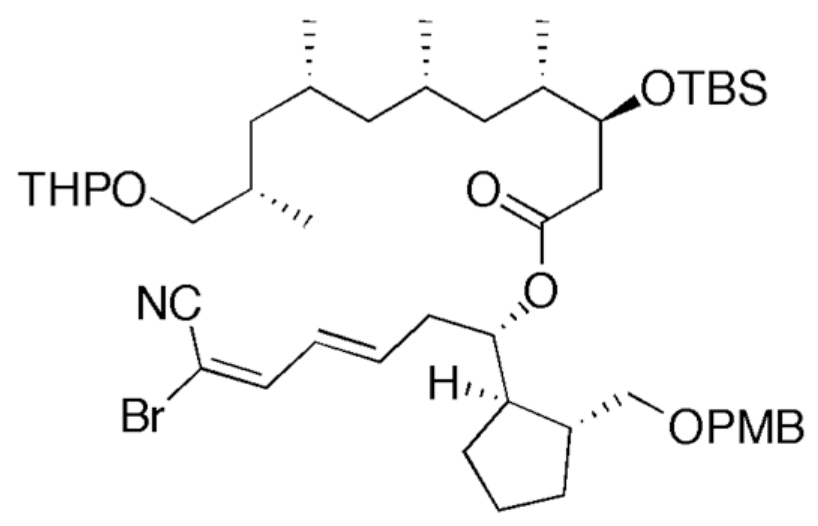

32

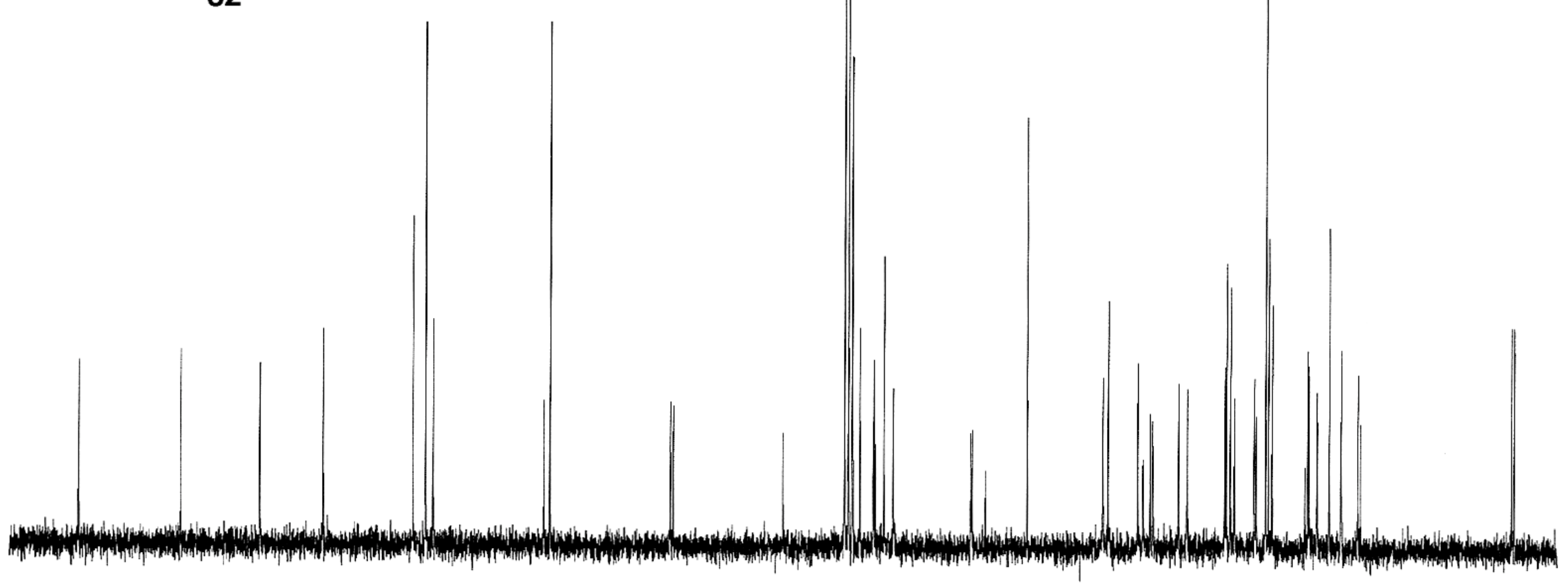

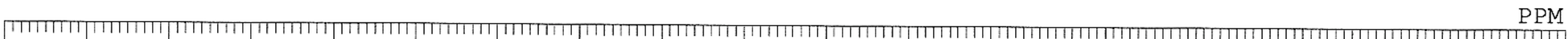

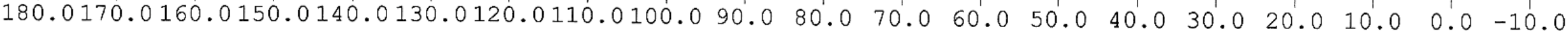




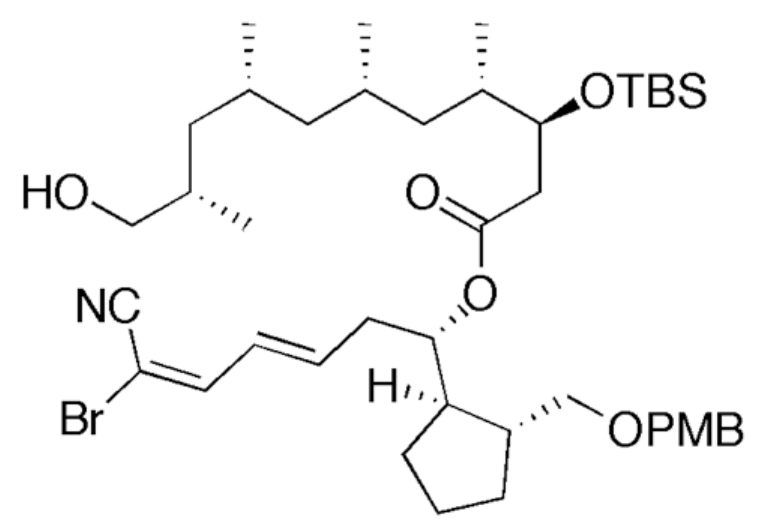

$32 a$

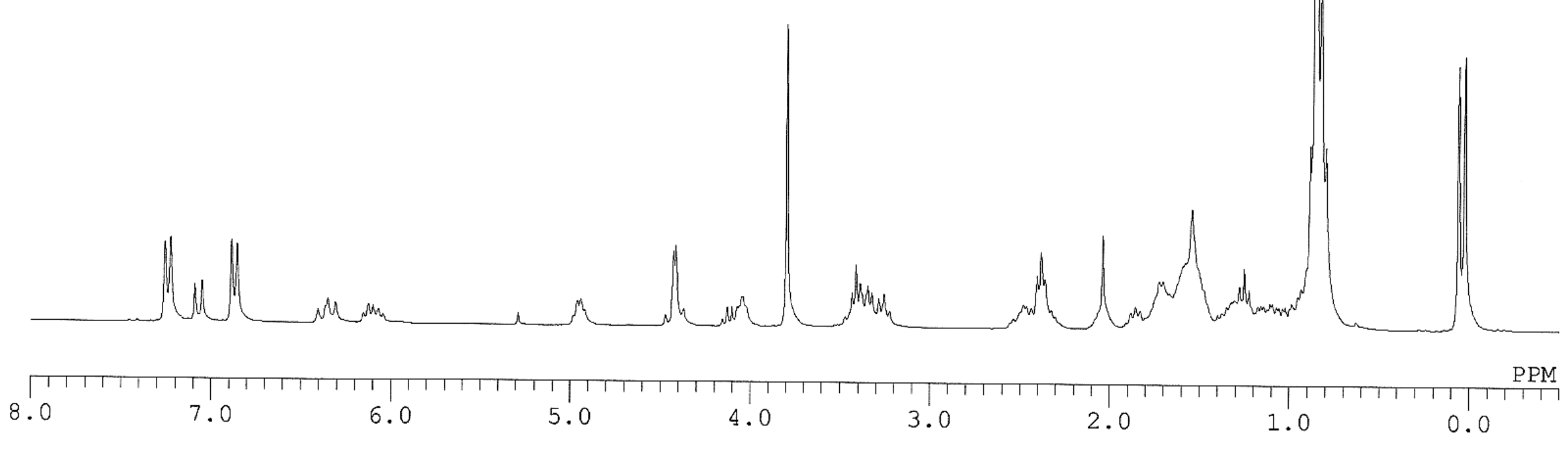




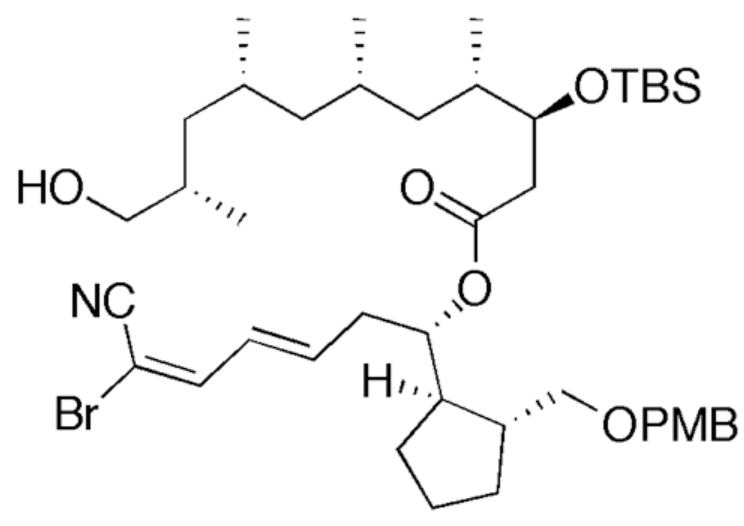

$32 a$
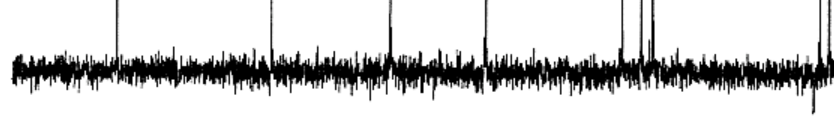

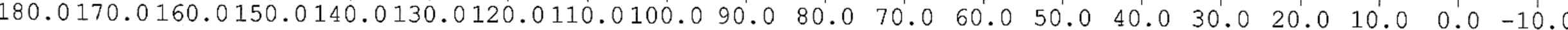




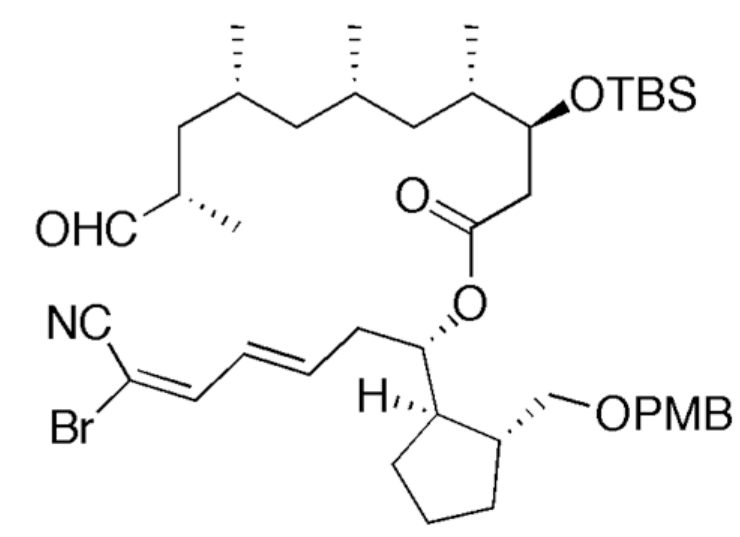

2

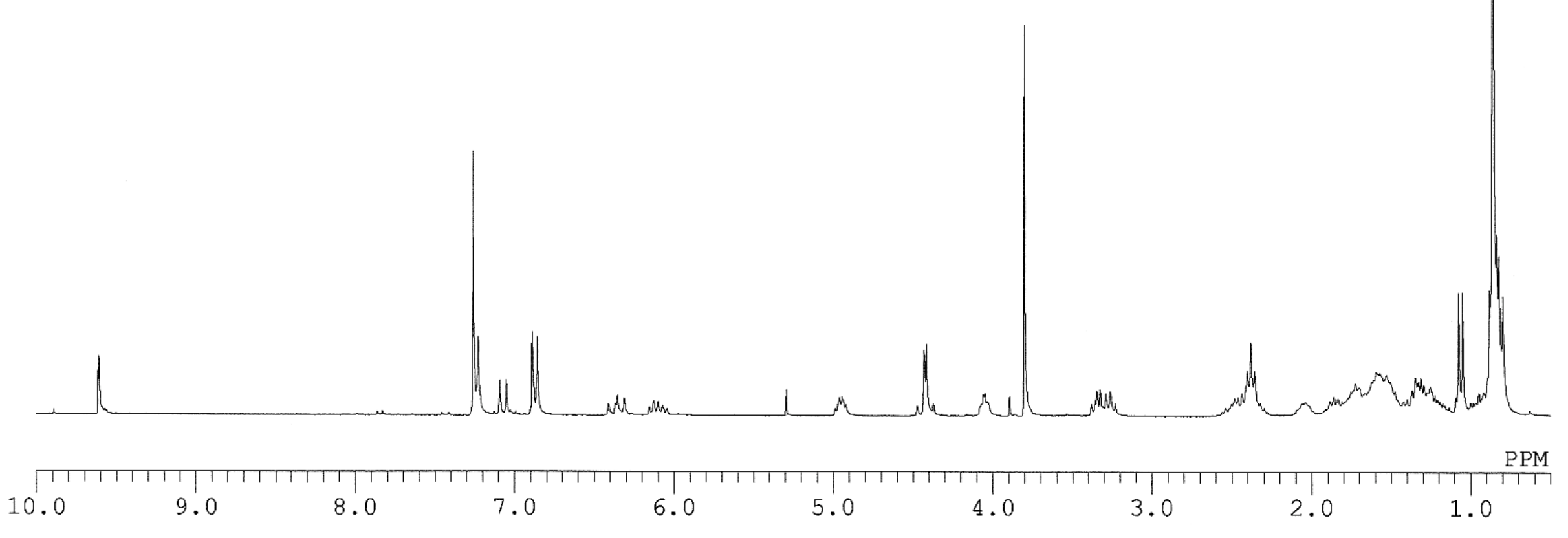

$S^{\prime}$

45 


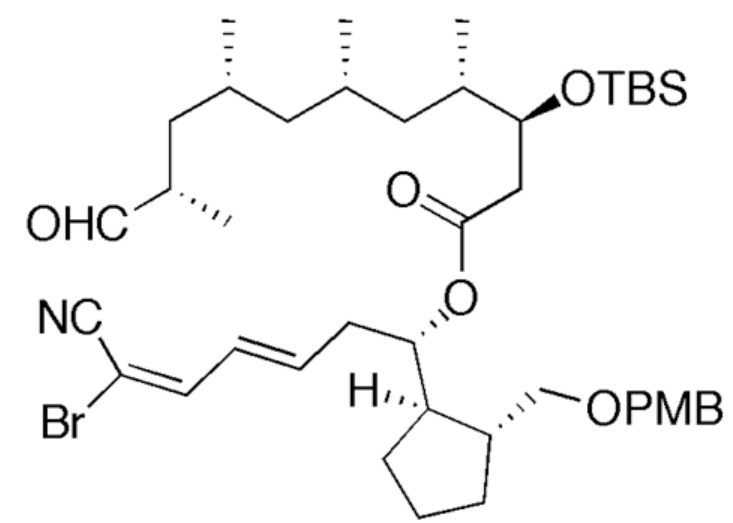

2

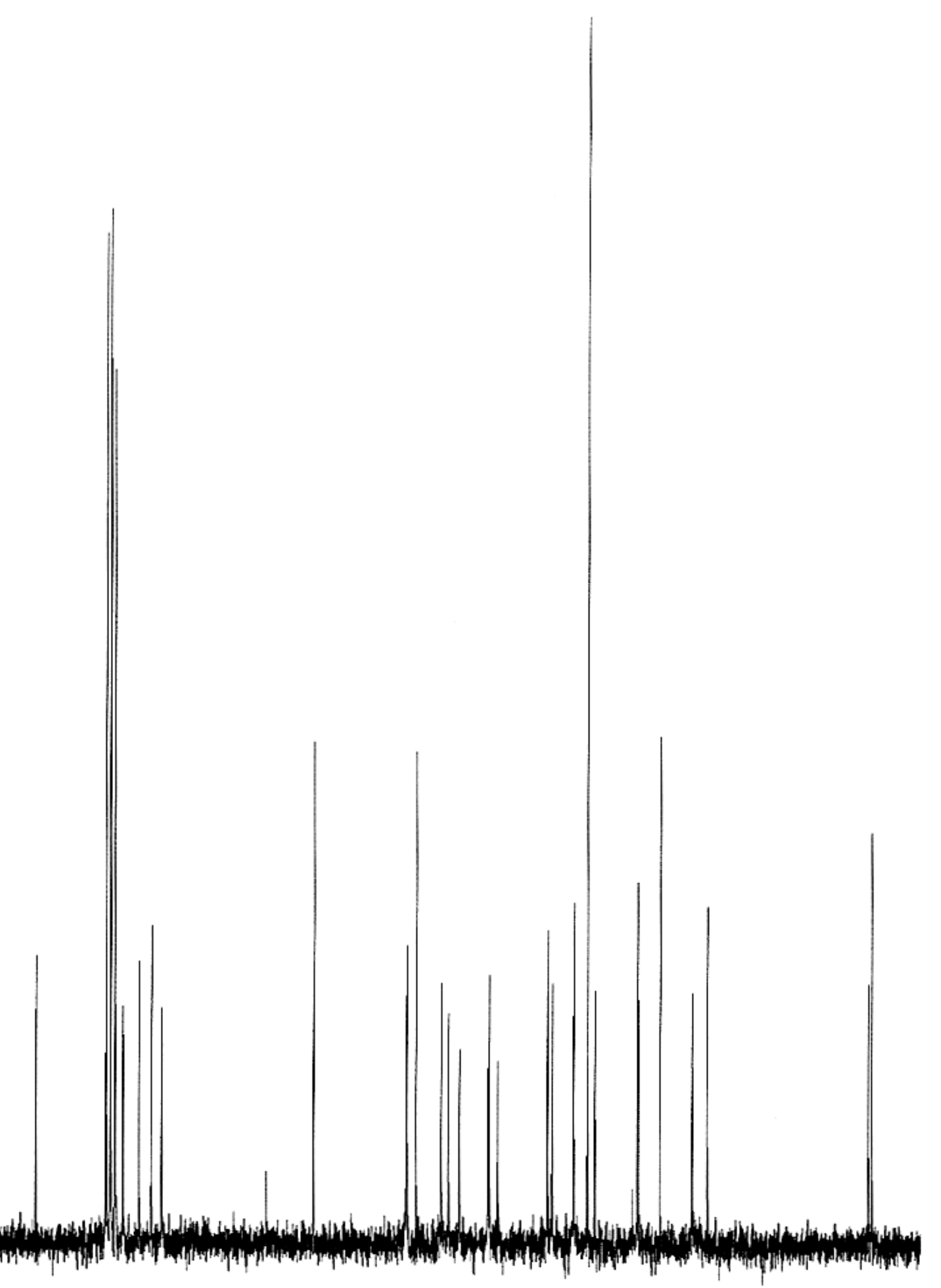

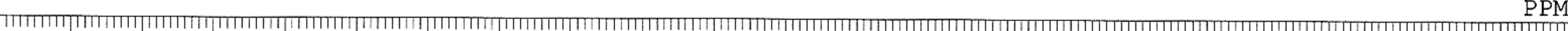

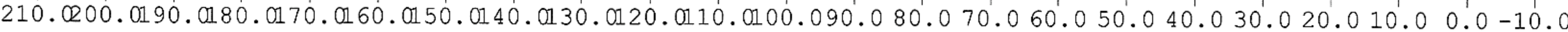




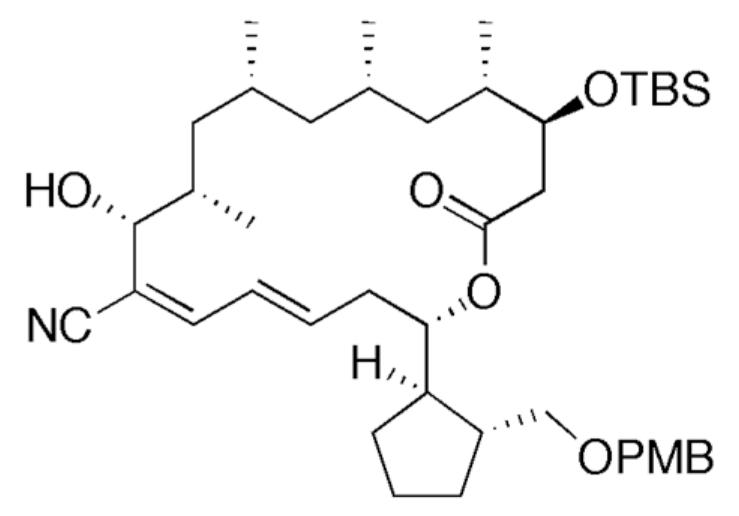

37
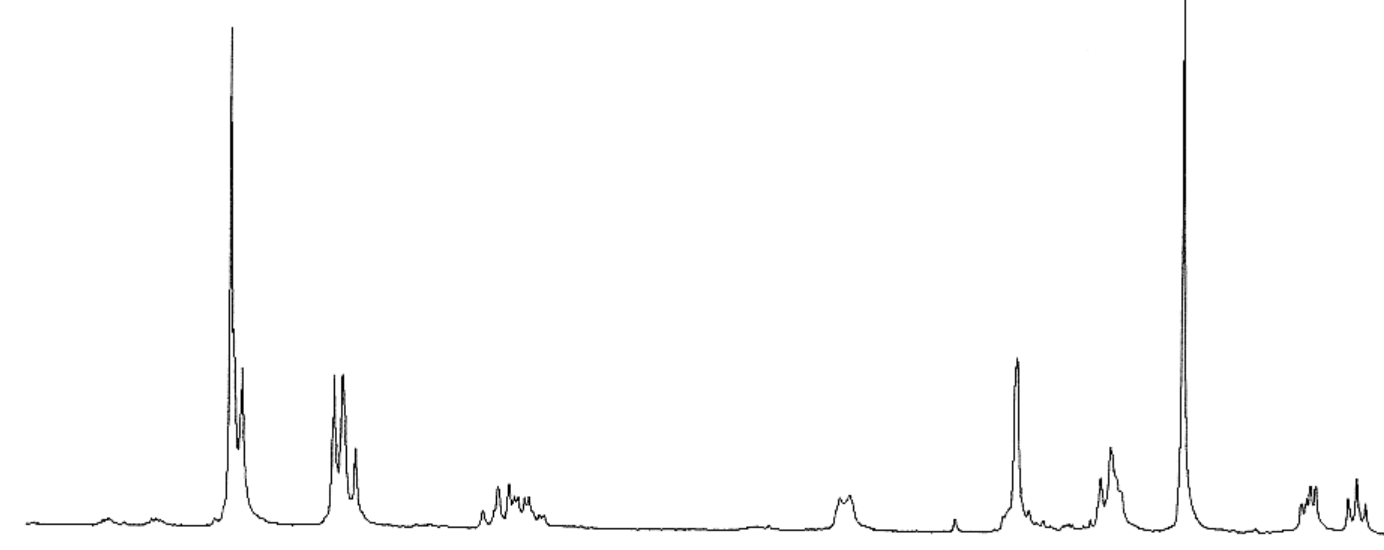
Mun humant

PPM

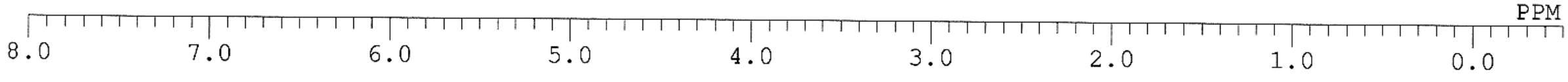



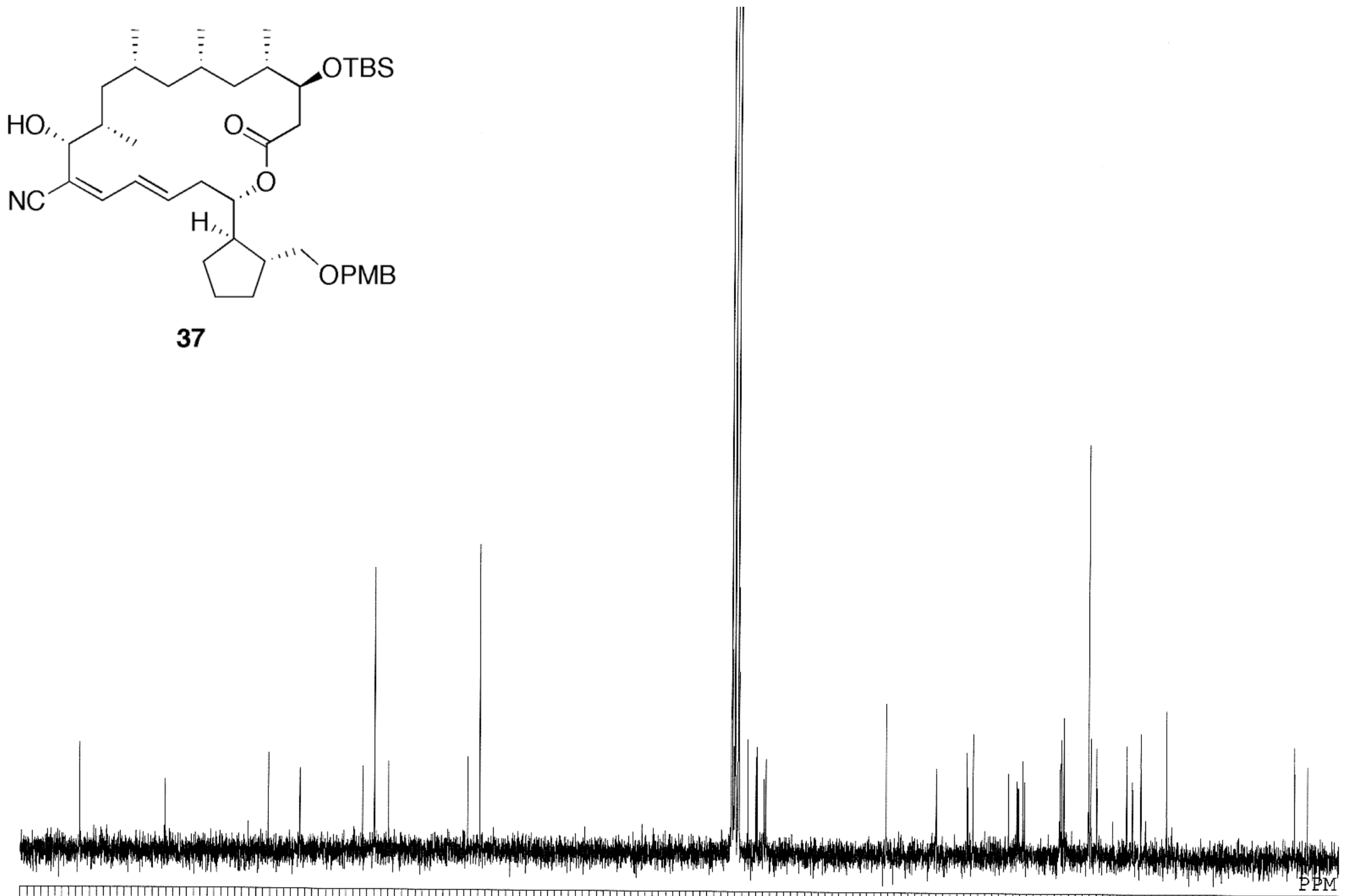

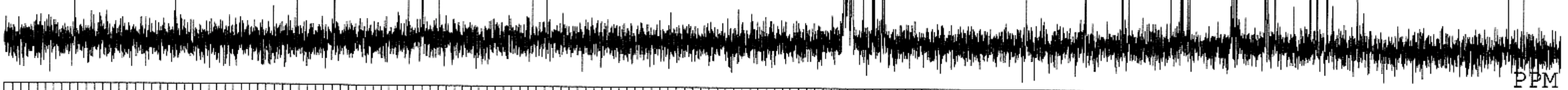

\begin{tabular}{ll|l|l|l|} 
&
\end{tabular}

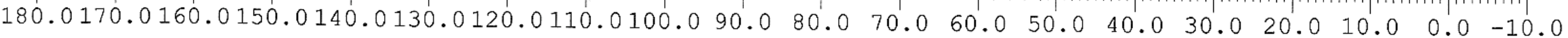




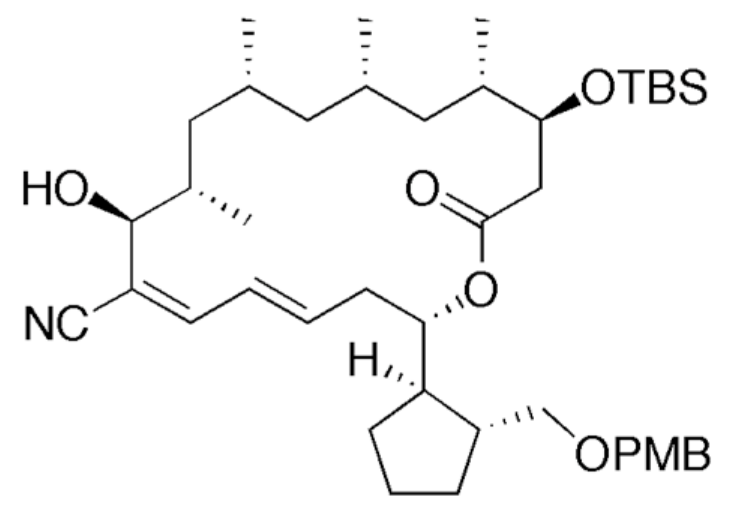

38

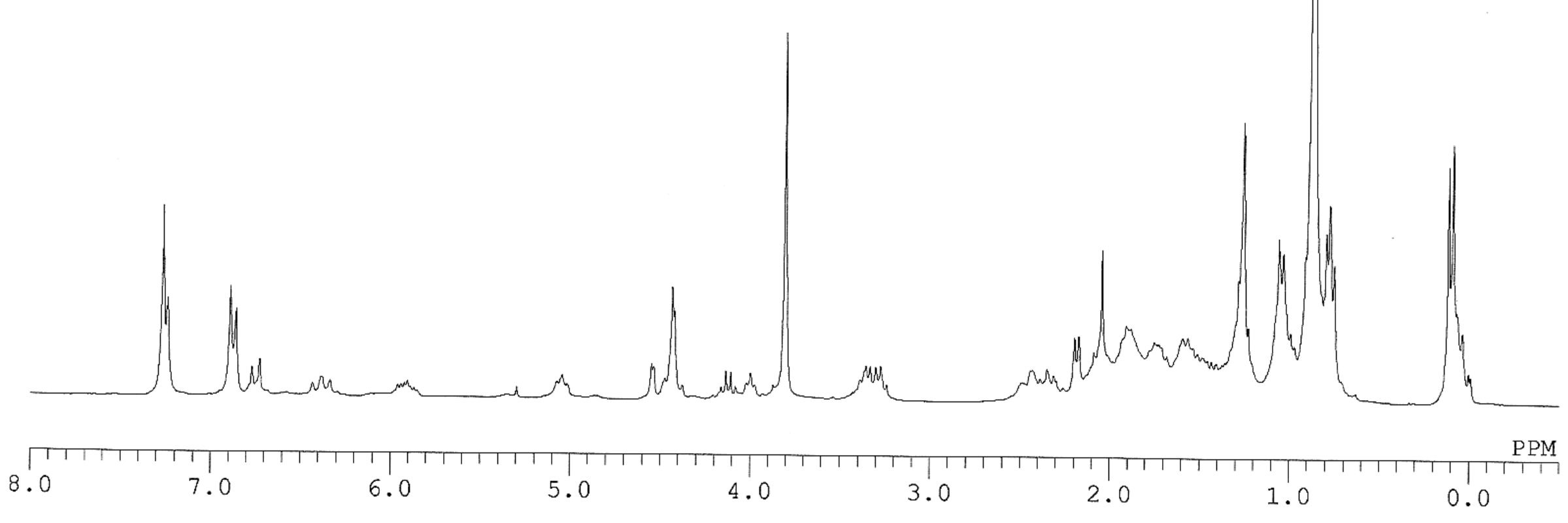




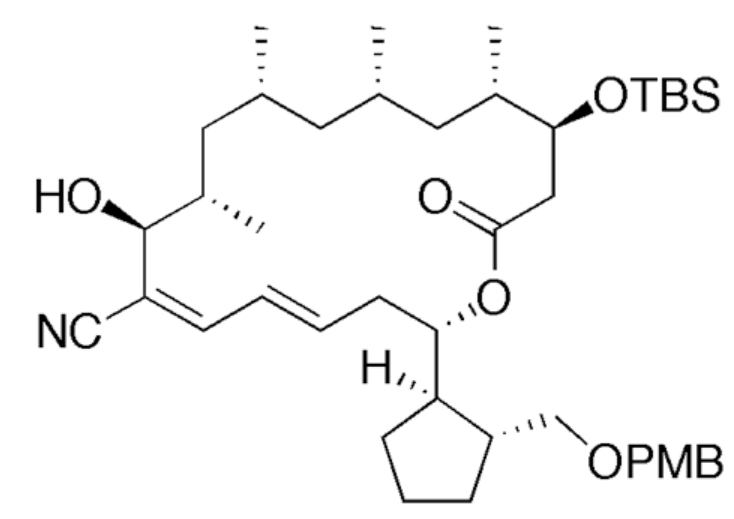

38

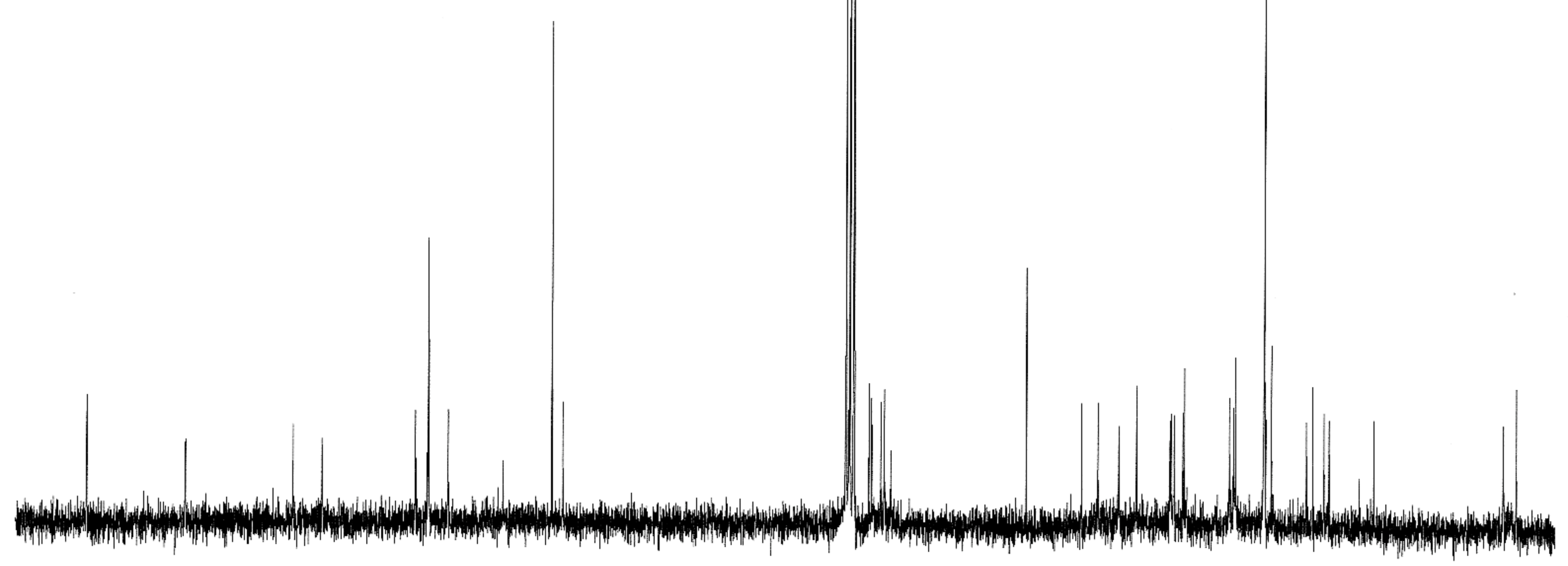

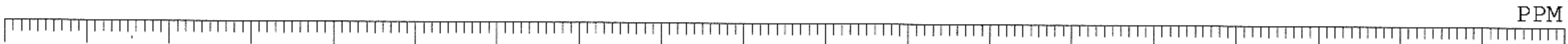

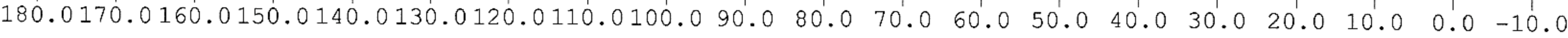

